\title{
1 Meta-analysis of the genetic loci of pigment pattern evolution in
}

\section{2 vertebrates}

3 Joel Elkin ${ }^{1, *}$, Arnaud Martin $^{2}$, Virginie Courtier-Orgogozo ${ }^{3}$, M. Emília Santos ${ }^{1, *}$

$4 \quad{ }^{1}$ Department of Zoology, University of Cambridge, Cambridge, UK

5 'Department of Biological Sciences, The George Washington University, Washington, DC, 6 USA.

$7 \quad{ }^{3}$ Institut Jacques Monod, Université de Paris, CNRS, Paris, France

$8 \quad$ *Authors for correspondence: joel.elkin416@gmail.com and es754@cam.ac.uk

9

10 Abstract

11 Vertebrate pigmentation patterns are amongst the best characterised model systems for studying the genetic basis of adaptive evolution. The wealth of available data on the genetic basis for pigmentation evolution allows for meta-analysis of trends and quantitative testing of evolutionary hypotheses. We employed Gephebase, a database of genetic variants associated with natural and domesticated trait variation, to examine trends in how cisregulatory and coding mutations contribute to vertebrate pigmentation phenotypes, as well as factors that favour one mutation type over the other. We found that studies with lower ascertainment bias identified higher proportions of cis-regulatory mutations, and that cisregulatory mutations were more common amongst animals harboring a higher number of pigment cell classes. We classified pigmentation traits firstly according to their physiological basis and secondly according to whether they affect colour or pattern, and identified that carotenoid-based pigmentation and variation in pattern boundaries are preferentially associated with cis-regulatory change. We also classified genes according to their developmental, cellular, and molecular functions. We found that genes implicated in upstream developmental processes had greater cis-regulatory proportions than downstream cellular function genes, and that ligands were associated with higher cis-regulatory proportions than their respective receptors. Based on these trends, we discuss future directions for research in vertebrate pigmentation evolution. 


\section{Introduction}

One of the central goals of evolutionary biology is to understand the genetic basis of organismal diversity. Determining which genes and mutations underlie adaptive traits is essential for understanding how evolutionary forces shape organismal variation (Barrett and Hoekstra, 2011). In this regard, vertebrate pigmentation is a powerful system for integrating historically disparate fields of evolutionary research, and ultimately identifying the genetic mechanisms underlying evolutionary change (Cuthill et al., 2017; Hubbard et al., 2010; Kronforst et al., 2012; Orteu and Jiggins, 2020).

Vertebrate pigmentation offers a diverse array of phenotypes, with intra- and interspecific variation ranging from whole-body colour changes, to highly localised pattern alterations (Figure 1). Similarly, the adaptive significance of pigment patterns can be attributed to multiple distinct selection pressures, including thermoregulation, camouflage, aposematism, sexual display, and ultraviolet protection (Protas and Patel, 2008). The rapid evolution of vertebrate pigmentation patterns, and their evolutionary significance, allows for both mapping of individual mutations to their resultant phenotypes, and inference of the evolutionary pressures driving the selection of said phenotypes. As such, there have been many studies identifying loci associated with a wide range of pigmentation phenotypes in different vertebrate taxa. A meta-analysis of these individual case studies may reveal broad trends underlying pigment pattern evolution and help to inform the future direction of vertebrate pigmentation research. Here, we first outline the basic biology of vertebrate pigmentation, as well as the key differences between different vertebrate clades. We then utilise a dataset of vertebrate pigmentation literature to analyse trends in the underlying genetics. For this purpose, we used Gephebase (https://www.gephebase.org/) - a knowledge base dedicated to the compilation of literature on genes and mutations underlying natural and domesticated organismal variation in Eukaryotes (Courtier-Orgogozo et al., 2020). Gephebase gathers published data on evolutionarily relevant mutations, each entry representing a causal association between an allelic change at a given locus and trait variation between individuals or species. Each entry includes information relating to the species/population, the type of trait, the gene, the nature of the mutation(s), whether they represent null alleles, and the study that identified it. Using the vertebrate pigmentation entries in this database, we focused on the relative abundance of cis-regulatory and coding mutations contributing to vertebrate pigmentation evolution. Finally, we discuss the direction of future vertebrate pigmentation research and the role to be played by recent model systems and innovative approaches. 

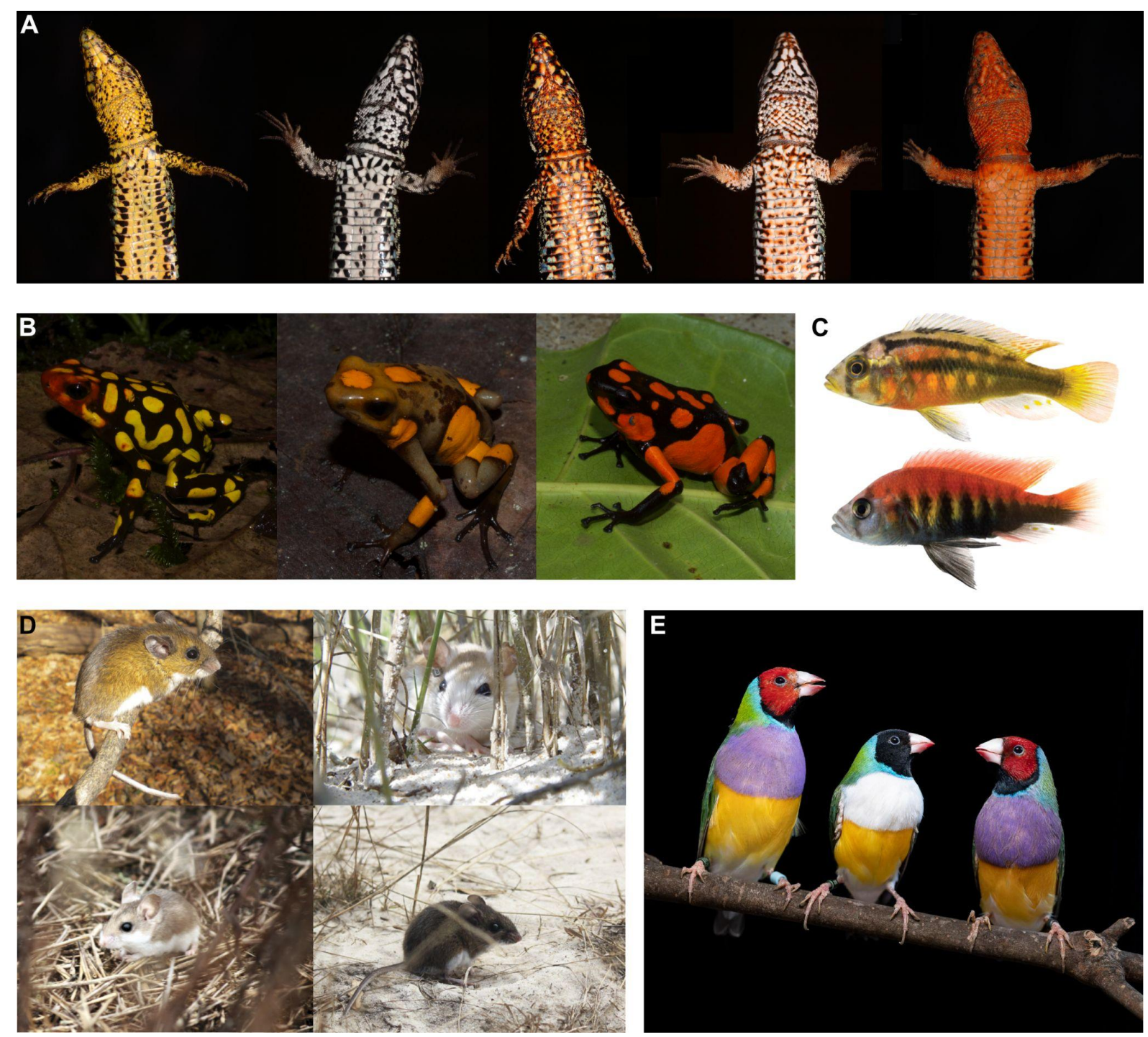

Figure 1. Examples of vertebrate colour pattern diversity. A: Sympatric colour morphs of the

European common wall lizard (Podarcis muralis) (Andrade et al., 2019). The colour morphs differ in a range of key morphological, physiological, or behavioural traits. Photographs courtesy of Pedro Andrade and Miguel Carneiro. B: Allopatric morphs of harlequin poison frogs (Oophaga histrionica complex). Amphibian colour patterns are extremely underrepresented in pigmentation evolutionary genetic studies. Photographs courtesy of Roberto Marquez. C: Two species of Lake Victoria cichlids. Pundamilia nyererei (top) and Haplochromis sauvagei (bottom) showing differences in horizontal stripes and vertical bars (Kratochwil et al., 2018). Photographs courtesy of Claudius Kratochwil. D: Different species of Peromyscus mice showing differences in colour phenotypes $-P$. maniculatus nubiterrae (top left, image credit to Evan $\mathrm{P}$ Kingsley), P. polionotus phasma (top right, image credit to JB Miller), P. polionotus sumneri (bottom left, image credit to Nicole Bedford) and $P$. gossypinus (bottom right, image credit to Nicole Bedford). Differences in melanic coat colouration correlate with the colour of the background substrate and evolved as a result of 
strong predation. Photographs adapted from Bedford and Hoekstra, 2015. E: Red and black head colour polymorphism in the Gouldian finch (Erythrura gouldiae), morphs display differences in aggressivity and reproductive success (Toomey et al., 2018). Photograph courtesy of Ricardo Jorge Lopes and Miguel Carneiro.

\section{Vertebrate pigmentation}

In vertebrates, most colour patterns derive from specialised pigment cells which produce either pigments or reflective structures. These cells derive from the migratory neural crest cell population, which emerges from the dorsal neural tube during early vertebrate development (Lapedriza et al., 2014). Neural crest cells then delaminate and undergo some of the longest migrations of any embryonic cell type to give rise to multiple derivatives such as neurons and glia of the peripheral nervous system, smooth muscle, craniofacial cartilage and bone, and pigment cells (Simões-Costa and Bronner, 2015).

Across vertebrate clades there is considerable diversity in the cell types producing colours. In fish, amphibians, and non-avian reptiles, there are multiple distinct classes of pigmented and structurally coloured cells, called chromatophores. These classes contain different combinations of pigments and/or reflective structures, and therefore exhibit different ranges of colours. Across these clades up to at least nine chromatophore classes are recognised. The most common chromatophore classes that utilise pigments are melanophores (brown/black melanin pigments) and xanthophores (yellow/orange carotenoid pigments). These cells produce pigment-based colour via the deposition of their respective pigment molecules, which selectively absorb specific wavelengths of light. In contrast, structural colouration results from the presence of reflective structures, such that structural colour is variable depending on the angle from which it is viewed. The most common structural chromatophore is the iridophore, which appears silvery or blue due to the arrangement of layered purine platelets of variable size, shape, and arrangement (Parichy, 2021; Singh and Nüsslein-Volhard, 2015).

Rarer chromatophore classes include red erythrophores and blue cyanophores, as well as two distinct classes of white leucophores with different regulatory profiles, developmental origins, and chemical compositions (Goda and Fujii, 1995; Huang et al., 2021; Lewis et al., 2019). Each chromatophore class present in an organism goes through extensive cell movements and cell-cell interactions to form a final colour pattern. Variation in the abundance, combinations, and arrangements of chromatophores generates the intricate and diverse colour patterns seen in fish, amphibians, and reptiles. 
In contrast, mammals and birds have independently lost most pigment cell diversity and mainly retain only one pigmentary cell type, the melanocyte (equivalent to the melanophore) (Kelsh et al., 2009). Melanocyte differentiation and development remains highly conserved between vertebrates, but differences exist. Unlike melanophores, melanocytes produce two melanin pigment types in different shades - brownish-black eumelanin, and reddish pheomelanin. The ability to switch melanogenesis between eumelanin and pheomelanin production is specific to birds and mammals (McNamara et al., 2021). Mammals and birds develop complex pigmentation patterns by temporally and spatially regulating melanogenesis switching, as opposed to using different chromatophore classes for different colours. Furthermore, while other vertebrates retain pigments within the respective chromatophore, in birds and mammals melanin is secreted from melanocytes into the skin or the integumentary appendages, such as feathers and hairs (McNamara et al., 2021). Finally, birds additionally exhibit an array of yellow, orange and red colours due to the processing and accumulation of dietary carotenoid pigments (Toews et al., 2017).

\section{The role of cis-regulatory and coding mutations in evolution}

The extent to which evolution is predictable on the level of genetic variation is a long-standing topic in evolutionary biology. One important question concerns the relative prevalence of cisregulatory and coding sequence mutations (Carroll, 2008; Hoekstra and Coyne, 2007; Martin and Courtier-Orgogozo, 2017; Martin and Orgogozo, 2013; Stern and Orgogozo, 2009, 2008). It has been hypothesised that cis-regulatory mutations are more likely to contribute to evolutionary changes in morphology (Carroll, 2008). One reason for this is that cis-regulatory mutations are expected to have fewer pleiotropic effects when compared to coding mutations, mostly due to their highly modular nature conferring tissue specificity, affecting gene expression patterns without changing protein function. Conversely, protein coding sequences are less modular, and non-synonymous mutations are expected to affect protein function across every cell and tissue in which it is expressed. For the past three decades though, case studies have shown both types of mutations contributing to evolutionary change. Thus, trying to argue for the existence of a dichotomy in the relative frequency of both types of genetic change is too simplistic. Instead, we should strive to understand when one type of mutation is selected over the other (Stern and Orgogozo, 2008). For example, are different mutations associated with particular aspects of trait variation (e.g. colour versus pattern)? Do the cellular and developmental processes underlying a trait influence the nature of the mutations that can affect it? Do we see a shift in the role played by different types of mutation throughout evolutionary time? 
145 Here, we tackled these questions by examining the relative distribution of cis-regulatory and

146 coding mutations across vertebrate pigmentation evolution, and how the relative frequencies

147 of these mutation types associate with other factors, such as loci mapping strategy, type of

148 trait variation or types of genes involved. Moreover, by analysing the types of mutation

149 associated with the evolution of vertebrate pigmentation, we identify trends in the field and

150 discuss possible directions for future research. 
Results

152 Genetic variants associated with pigmentation are asymmetrically distributed across vertebrate clades

154 To examine the representation of different pigmentation systems across vertebrate evolutionary studies, we looked at the number of entries in Gephebase across five clades teleost fishes, amphibians, squamates, birds and mammals. All of the 363 vertebrate pigmentation entries belonged to one of these clades. The significant majority $(71.1 \%, \mathrm{n}=$ $258)$ of entries were mammals, whilst birds $(20.9 \%, n=76)$ were also highly prevalent (Table 1). Teleosts $(5.5 \%, n=20)$ and squamates $(2.2 \%, n=8)$ were scarcely represented, and amphibians were associated with only one entry $(0.3 \%)$. As such, clades in which multiple distinct chromatophore classes are found represent less than $10 \%$ of our dataset, in comparison to those clades which harbour only melanocytes and no other pigment cell classes. This taxonomic bias is attributable in part to how the field originated and evolved. For instance, the disproportionate representation of mammalian studies is likely a reflection of the extensive characterisation of the mouse coat colour genetics system, which has been studied for more than a century (Hoekstra, 2006). As a result, many of the key components of the melanin biosynthesis pathway were first identified in mice, and these components are often selected for investigation in other mammalian and bird systems.

Table 1: Number of entries in the vertebrate pigmentation Gephebase dataset in 2021 (see methods) according to vertebrate clade and taxonomic status. One entry corresponds to genetic variation at a given gene that has been found to contribute to pigmentation evolution in a given taxon.

\begin{tabular}{|l|l|l|l|l|}
\hline Gephebase entries & Domesticated & Intraspecific & Interspecific & Total by clade \\
\hline Teleosts & 2 & 10 & 8 & 20 \\
\hline Amphibians & 0 & 1 & 0 & 1 \\
\hline Squamates & 0 & 8 & 0 & 8 \\
\hline Birds & 54 & 18 & 4 & 76 \\
\hline Mammals & 177 & 79 & 2 & 258 \\
\hline Total by taxonomic status & 233 & 116 & 14 & 363 \\
\hline
\end{tabular}


We examined the relative prevalence of protein coding and cis-regulatory mutations across the dataset. Cis-regulatory mutations, and coding sequence mutations together account for 330 entries $(90.9 \%)$ out of the full dataset, with coding mutations being the majority (262 entries, $72.2 \%)$. The remaining classes of genetic variation $(9.1 \%)$ were gene amplification, gene loss, intronic mutations, and unknown (when the gene has been identified but the exact mutation(s) have not) (Figure 2A). The overall prevalence of coding mutations is in contrast to the hypothesis that cis-regulatory mutations have a greater likelihood of generating phenotypic change (Carroll, 2008). This may reflect the relative ease of identifying coding mutations compared with cis-regulatory changes (Stern and Orgogozo, 2008). Next we analysed the relationship between the types of mutations and the methodology used to identify them.

\section{Study methodologies with less ascertainment bias exhibit slightly higher proportion of cis-regulatory mutations}

Three methodology categories are represented in the dataset - Candidate Gene, Linkage Mapping, and Association Mapping (Courtier-Orgogozo et al., 2020). Candidate gene studies exhibit the highest ascertainment bias and may be expected to identify a higher proportion of coding mutations. Indeed, many candidate gene studies have historically focused on identifying amino-acid changes within coding regions in new species, based on previous findings in other species. However, they also facilitate comparisons across broad taxonomic distances compared with other mapping approaches. In contrast, both linkage and association mapping studies start with a phenotypic difference and attempt to pin it to a sequence change, at least as a locus interval. Linkage mapping involves crossing populations to generate recombinant hybrids, and thus can only map variation between closely related organisms which are interfertile. However, such studies are usually less biased than candidate gene approaches in their detection of causative loci, depending on the resolution and coverage of the mapping. Finally, association mapping approaches involve identification of significant association within large, heavily intermixed populations, and typically have minimal ascertainment bias as a result. To account for potential differences between methodologies we plotted the proportion of cis-regulatory mutations for each method (Figure 2B).

As expected, candidate gene approaches identified the lowest proportion of cis-regulatory mutations (12.2\%) and was the only category below the dataset average. Linkage mapping had a higher proportion (23.8\%), and association mapping was higher still (42.6\%). All three of these methodology categories reported a higher overall proportion of coding than cisregulatory mutations (Figure $2 \mathrm{~B}$ ). As such, regardless of the method used, protein coding mutations underlie the majority of the investigated vertebrate pigmentation variation. The 
211 effect of study methodology on the cis-regulatory proportion appears to be that decreased

212 ascertainment bias increases the discovery of causal cis-regulatory mutations.

213 These results have to be taken with caution, since all methodologies will tend to favour the

214 identification of coding mutations. For example, once a candidate region is found by linkage

215 mapping or association mapping, it is still easier to find coding mutations contributing to the

216 trait of interest than cis-regulatory mutations: based on the genetic code it is easy to identify

217 mutations disrupting the amino acid sequence of the encoded protein whereas it is difficult to

218 predict cis-regulatory effects based on sequence alone. Furthermore, validation of cis-

219 regulatory mutations usually requires reporter constructs and transgenic animals, thus being 220 more time-consuming than the validation of coding mutations, which can often involve in vitro 221 assays.

222

223 Changes in cis-regulatory reporting over time do not fully explain the disparity in 224 mutation types

225 The Gephebase dataset includes studies published between 1993 and 2020 (Courtier-

226 Orgogozo et al., 2020). Owing to the increasing availability of genomic resources facilitating 227 linkage and association mapping in a broader range of model systems (Kratochwil and Meyer, 228 2015), we expected the cis-regulatory proportion of the dataset to increase over time. We 229 therefore examined the cumulative number of cis-regulatory and coding mutations over the 230 time period covered by the dataset, for each study methodology. We used this approach as 231 the low numbers of entries for each individual year made non-cumulative comparison 232 misleading - for instance, there were several years with no entries for a particular study 233 methodology. We found that cis-regulatory entries began to appear in the dataset later than 234 coding entries (Figure 2C and 2D). Prior to 2005 only a single cis-regulatory mutation was 235 identified, compared with 65 coding. However, past this point cis-regulatory entries were 236 added at approximately the same rate as coding, for each study methodology. Thus, although 237 the overall cis-regulatory proportion does increase over the entire time period covered, this is 238 largely due to coding mutation discovery beginning earlier.

239 We also did not observe an appreciable increase in the relative prevalence of linkage mapping 240 or association mapping studies. Taken together, this suggests that the overall trend is a slight 241 increase in cis-regulatory mutation reporting, but that differences in the relative prevalence of 242 different study methodologies are not sufficient to explain the disparity between cis-regulatory 243 and coding mutations. As such, it is possible that there is a discovery bias towards the 244 identification of coding mutations in all methods, or alternatively, that evolutionary variations 
in vertebrate pigmentation involve a higher proportion of coding mutations. In the next sections, we further examine this proposition with particular attention to research biases and

247 phenotypic categories.

249 The relative frequency of cis-regulatory and coding mutations holds in the absence of 250 the most represented genes in the dataset

251 Historically, most evolutionary studies have centred on the melanic mammalian and bird 252 pigmentation systems owing to the important knowledge in mice coat colour genetics. 253 Therefore, we further explored if the prevalence of protein coding mutations was due to the 254 overrepresentation of melanic pigmentation case studies. Mammal and avian melanic pigment 255 patterns are the result of dynamic switching between the synthesis of two types of melanin. 256 The switch between black eumelanin and reddish-brown pheomelanin is controlled by the melanocortin 1 receptor, MC1R (García-Borrón et al., 2005). Mc1r is the most represented gene in our dataset, with 87 entries that account for $26.4 \%$ of the dataset. The second-most represented gene in the dataset is kit, a cell-surface receptor that is essential for the expression of tyrosinase, a rate-limiting enzyme in melanin biosynthesis (Hou et al., 2000). 40 kit entries account for $12.1 \%$ of entries. Finally, the third-most represented gene is agouti signalling protein, asip. ASIP acts as an antagonist to MC1R - in the absence of ASIP, MC1R initiates a signalling cascade resulting in eumelanin production, while ASIP antagonism reverts the melanocyte to pheomelanin synthesis (García-Borrón et al., 2005). There are 33 asip entries, corresponding to $10 \%$ of the dataset.

The high representation of these three genes in Gephebase reflects their relevance in mammalian and other vertebrate systems, and particularly their frequent selection as candidate genes for further study. To remove a potential bias of methodology resulting from a focus on melanic genes, we performed the same analysis with these three entries - $m c 1 r$, kit, and asip - removed. When removing $m c 1 r$, kit, and asip entries from the dataset, the overall proportion of cis-regulatory mutations increases from $20.6 \%$ to $27.6 \%$, owing to the prevalence

272 of coding mutations amongst mc1r entries in particular (Figure 2E). The cis-regulatory 273 proportion of all three methdology categories increases, and association mapping remains the 274 category with the highest cis-regulatory proportion, followed by linkage mapping (Figure 2E). 275 Still, coding mutations remain the majority of entries for each type of experimental evidence. 276 Taken together, the overrepresentation of these melanic case studies does not explain the higher prevalence of protein coding mutations in the vertebrate pigmentation dataset. 


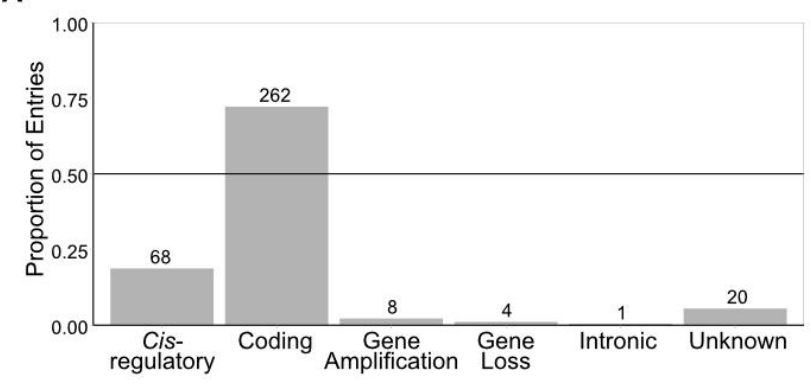

C

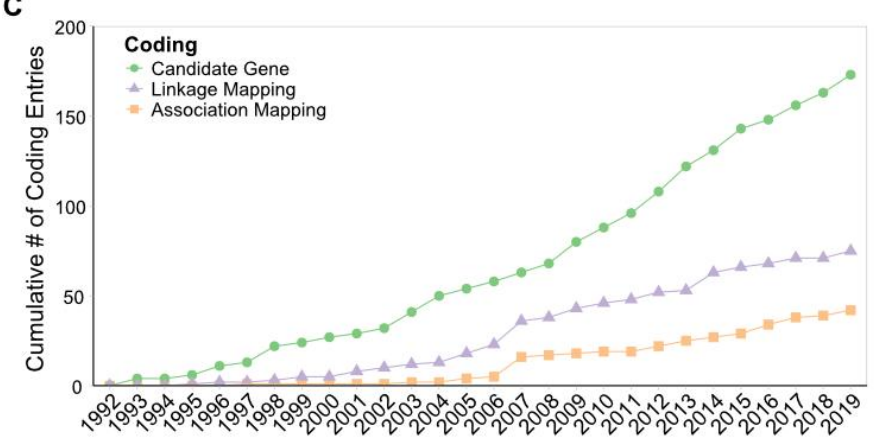

D

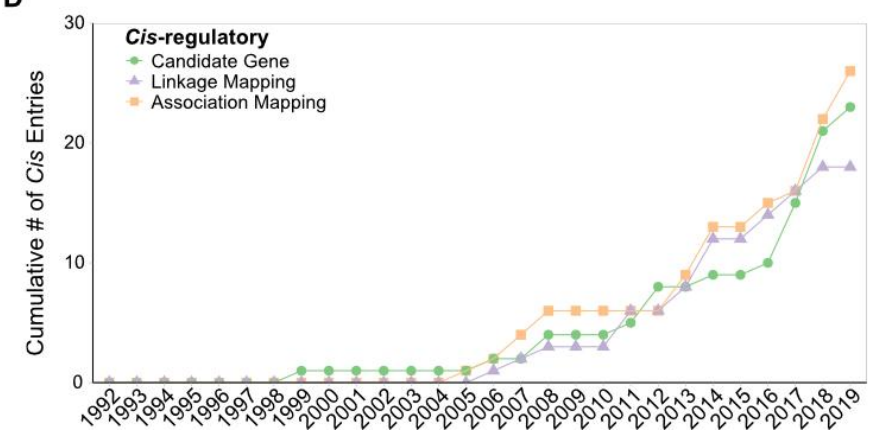

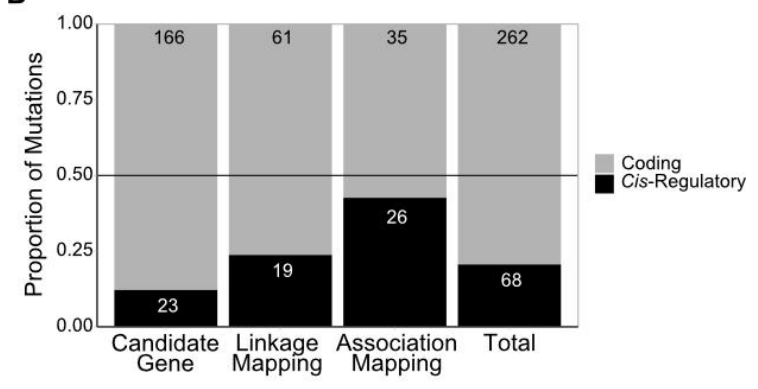

E

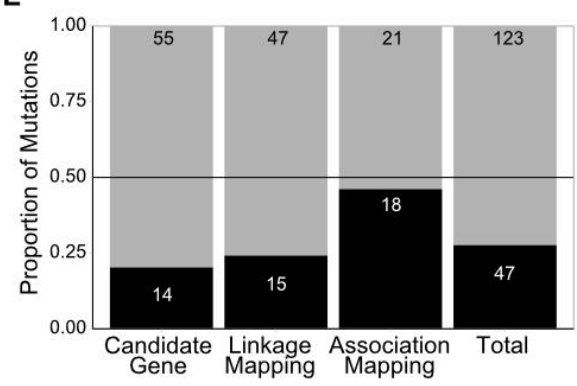

281 Figure 2. A: The relative proportions of all of the mutation types identified. B: The cisregulatory and coding mutations associated with each study methodology, as well as the total proportion of the dataset. C: The cumulative number of coding mutations of each study methodology over the time period recorded in the Gephebase dataset. D: The cumulative number of cis-regulatory mutations of each study methodology over the time period recorded in the Gephebase dataset. E: The cis-regulatory and coding mutations associated with each study methodology, with mc1r, asip and kit entries removed. The numbers above (A) or within ( $B$ \& E) each bar represent the number of entries in that category. The grey horizontal line is at 0.5 .

291 The proportion of coding mutations is higher for studies of domesticated and intraspecific variation than for interspecific variation 
293 It has been previously hypothesised that different kinds of mutation occur with different 294 frequencies during short-term and long term evolution with coding mutations being more 295 common across short-term evolution, and thus shorter taxonomic distances (Stern and 296 Orgogozo, 2009, 2008). Over shorter periods of time, mutations with deleterious pleiotropic 297 effects might be selected for if alternative, less pleiotropic mutations do not immediately 298 appear. Whereas, over long periods of time, non-optimal mutations will be tested in a variety 299 of environments and there will be more opportunity for adaptive mutations without pleiotropic 300 effects to appear and be selected for. In addition, contexts of artificial selection and favourable breeding conditions by humans can overcome the cost of mutations that would normally be counter-selected in the wild (Cieslak et al., 2011; Courtier-Orgogozo and Martin, 2020; Hanly et al., 2021). To test if the same is true for vertebrate pigmentation systems, we plotted the proportion of cis-regulatory mutations by taxonomic status. The dataset includes three categories of taxonomic status - Domesticated, Intraspecific, and Interspecific. Gephebase also includes 'Intergeneric or higher', but no vertebrate colouration entries were assigned this category. The domesticated category included cases of artificial selection by breeders and fanciers, with pigment trait variations being directly selected in most cases. The intraspecific category contained studies that investigated natural phenotypic differences between morphs of the same species. Finally, interspecific entries were all those that used pairs of taxa above the species level.

312 Domesticated and intraspecific variation show a similarly low proportion of cis-regulatory mutations (16.6\% and 23.1\%, respectively; Figure 3A, Figure S1). In contrast, interspecific variation showed a notably higher proportion of cis-regulatory mutations $(72.7 \%)$, suggesting that their prevalence may increase with increasing taxonomic distance (Figure 3A). This result has to be taken with caution as the number of studies addressing vertebrate pigmentation variation between species is extremely low - only a total of 11 entries were interspecific.

318 Further, 6 out of these 11 case studies were teleost fish entries, which have multiple pigment cell types which could influence the mutation proportion (Figure S2). The low number of interspecific studies together with low clade diversity, limits the examination of trends across large evolutionary timescales and may reflect an underexplored aspect of vertebrate pigmentation evolution.

The proportion of coding mutations is higher in mammal and bird studies than in teleosts, amphibians, and squamates studies

326 The prevalence of coding mutations could be associated with the disparity in representation 327 of different vertebrate clades. Birds and in particular mammals constitute the significant 
majority of entries (91.8\%, $\mathrm{n}=303$ combined), with teleosts, amphibians, and squamates being much rarer $(8.2 \%, n=27$ combined). These clades have divergent pigmentation systems, and notably only teleosts, amphibians, and squamates utilise multiple developmentally distinct classes of pigment cells. This may cause differences in evolutionary trends. For instance, the development of distinct pigment cell classes from a shared neural crest origin increases the likelihood of coding sequence mutations, in genes contributing to pigment cell development, having pleiotropic effects . Similarly, genes implicated in direct cellular interaction might be expected to suffer negative effects from coding sequence mutations, owing to the specificity of recognition that is typical of signalling molecules and their receptors. We therefore examined whether clades with distinct pigmentation systems lead to differences in the mutation proportion. For this purpose, we plotted the proportion of mutations by the five vertebrate clades (Table 1, Figure 3B). The only amphibian entry in the dataset was coding. Excluding amphibians, mammals had the lowest proportion of cis-regulatory changes $(16.2 \%)$. Birds had a similarly low cis-regulatory proportion $(21.7 \%)$. In contrast, squamates and teleosts both showed higher rates of cis-regulatory change - $50 \%$, and $55.0 \%$, respectively.

Although the low number of entries associated with multiple chromatophore pigment systems does preclude drawing definitive conclusions, this trend fits with the hypothesis that variation in pigmentation systems utilising multiple pigment cell classes exhibit a higher proportion of cis-regulatory mutations. Teleosts, amphibians, and squamates combined had a cisregulatory proportions of $55.5 \%$, compared with $17.5 \%$ for birds and mammals combined. Notably, teleosts exhibited a much higher proportion of interspecific studies than the dataset average - 6 of the 18 teleost entries were interspecific (Figure S2). The strong association between teleost entries and interspecific comparison makes it difficult to conclude which (if either) is the more important factor in yielding higher cis-regulatory proportions. Although, when taking into account only the intraspecific cases, the proportion of cis-regulatory mutations is still higher in teleosts, amphibians, and squamates (42.1\%, 8 out of 19) than in birds and mammals $(23.6 \%, 17$ out of 72 ) (Figure S2). A larger sample of studies conducted in model systems harbouring multiple pigment cell classes, together with more interspecific studies in other clades, would provide valuable insight in this regard. 
A

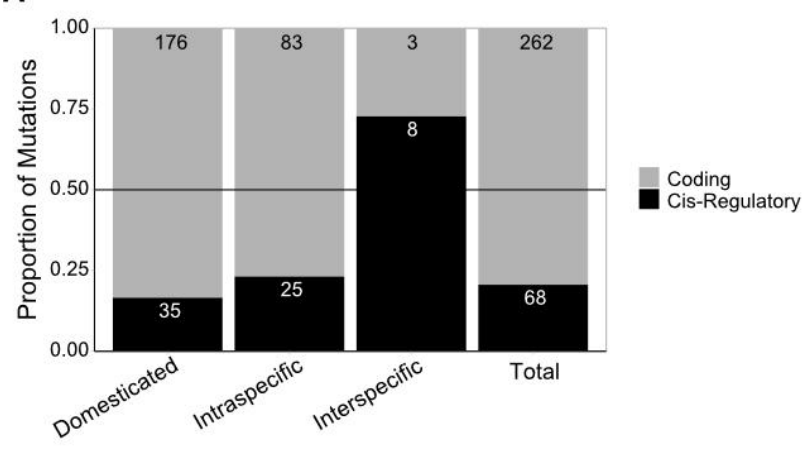

B

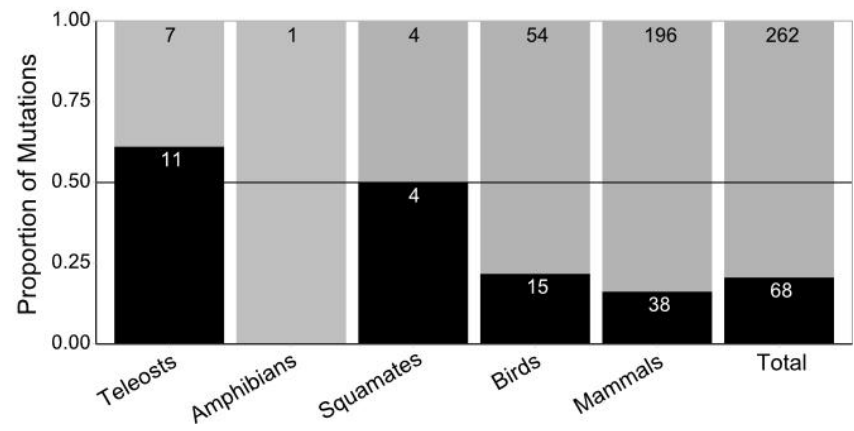

360 Figure 3. A: The proportion of cis-regulatory and coding mutations associated with each 361 taxonomic status, as well as the total proportion for the dataset. B: The proportion of cisregulatory and coding mutations associated with each clade. The numbers within each bar represent the number of entries in that category. The grey horizontal line is at 0.5 .

Types of phenotypic variation associated with coding versus cis-regulatory mechanisms

367 Differences in the nature of phenotypic variations may be associated with distinct types of genotypic change. For instance, loss of pigmentation may be more likely to result from lossof-function coding sequence changes, whereas patterning changes could be preferentially driven by cis-regulatory mutations due to their high spatial modularity reducing pleiotropic

371 effects (Orteu and Jiggins, 2020). To determine whether there are differences between colour

372 loss, colour tuning, and pattern variation, we assigned different phenotype categories to each 373 entry (Table 2).

374 Firstly, one of seven categories was assigned reflecting the nature of the phenotype in terms 375 of the distribution of colour across the body - pheomelanism, eumelanism, dilution, amelanism, 376 white spotting, carotenoid change, or carotenoid loss (Table 2). All of these categories 377 encompassed melanic traits except for carotenoid change and loss. Each entry was assigned 
to one of these categories on the basis of both the visible phenotype as well as the molecular

379 mechanism involved. For example, a phenotype involving patchy regions of white

380 pigmentation could be assigned to amelanism or white spotting, depending on whether

381 pigment synthesis or pigment cell migration was impaired.

382 Secondly, we separately assigned each entry to colour shift or pattern alteration, on the basis

383 of whether that phenotype represented a shift in colour or a change to spatial pattern 384 boundaries (Table 2).

Table 2: Summary of phenotype categories: assignment criteria for each phenotype category, and the total number of entries in the dataset for which that category was assigned.

\begin{tabular}{|c|c|c|c|}
\hline Category Name & Criteria for Assignment & $\begin{array}{l}\text { Number } \\
\text { of Entries }\end{array}$ & Example \\
\hline \multicolumn{4}{|c|}{ Colour loss versus colour tuning } \\
\hline Pheomelanism & $\begin{array}{l}\text { A phenotype exhibiting increased abundance of } \\
\text { pheomelanin relative to eumelanin, through } \\
\text { changes to melanogenic switching or production of } \\
\text { either melanin type. This includes phenotypes in } \\
\text { which eumelanin synthesis is absent or reduced } \\
\text { such that pheomelanin is relatively more prevalent. }\end{array}$ & 61 & $\begin{array}{l}\text { A missense mutation in MC1R } \\
\text { is associated with the red } \\
\text { phenotype in domesticated } \\
\text { donkeys (Abitbol et al., 2014). }\end{array}$ \\
\hline Eumelanism & $\begin{array}{l}\text { A phenotype exhibiting increased abundance of } \\
\text { eumelanin relative to pheomelanin, through } \\
\text { changes to melanogenic switching or production of } \\
\text { either melanin type. This includes phenotypes in } \\
\text { which pheomelanin synthesis is absent or reduced } \\
\text { such that eumelanin is relatively more prevalent. }\end{array}$ & 71 & $\begin{array}{l}\text { A loss-of-function SNP in } \\
\text { ASIP is associated with 'black } \\
\text { panther' phenotype melanistic } \\
\text { leopards (Schneider et al., } \\
\text { 2012). }\end{array}$ \\
\hline Dilution & $\begin{array}{l}\text { A phenotype in which both eumelanin and } \\
\text { pheomelanin synthesis is reduced (but not lost) } \\
\text { across one or several tissues. }\end{array}$ & 20 & $\begin{array}{l}\text { A melanophilin splice site SNP } \\
\text { leads to exon skipping and } \\
\text { coat colour dilution in } \\
\text { domesticated rabbits (Lehner } \\
\text { et al., 2013). }\end{array}$ \\
\hline Amelanism & $\begin{array}{l}\text { A phenotype characterised by a loss of melanin } \\
\text { production across one or several tissues. Includes } \\
\text { conditions variably defined as albinism and } \\
\text { leucism. }\end{array}$ & 42 & $\begin{array}{l}\text { Three separate tyrosinase } \\
\text { coding mutations are } \\
\text { associated with } \\
\text { oculocutaneous albinism in } \\
\text { three species of frog (Miura et } \\
\text { al., 2017). }\end{array}$ \\
\hline
\end{tabular}


bioRxiv preprint doi: https://doi.org/10.1101/2022.01.01.474697; this version posted January $2,2022$. The copyright holder for this preprint (which was not certified by peer review) is the author/funder, who has granted bioRxiv a license to display the preprint in perpetuity. It is made available under aCC-BY-NC-ND 4.0 International license.

\begin{tabular}{|c|c|c|c|}
\hline $\begin{array}{l}\text { Loss of carotenoid } \\
\text { coloration }\end{array}$ & $\begin{array}{l}\text { A phenotype resulting from the inability to uptake or } \\
\text { process dietary carotenoids causing total loss of } \\
\text { carotenoid-based pigmentation. }\end{array}$ & 2 & $\begin{array}{l}\text { A splice site mutation in } \\
\text { SCARB1 inhibits cellular } \\
\text { carotenoid uptake, leading to } \\
\text { a total loss of carotenoid } \\
\text { pigmentation in white canaries } \\
\text { (Toomey et al., 2017). }\end{array}$ \\
\hline $\begin{array}{l}\text { Change in carotenoid } \\
\text { coloration }\end{array}$ & $\begin{array}{l}\text { A phenotype resulting from changes to the relative } \\
\text { or overall abundance of carotenoid-based pigments } \\
\text { in the body. }\end{array}$ & 6 & $\begin{array}{l}\text { Gain of expression of a } \\
\text { carotenoid ketolase, } \\
\text { CYP2J19, is responsible for } \\
\text { processing yellow carotenoids } \\
\text { to produce red } \\
\text { ketocarotenoids in red } \\
\text { canaries (Lopes et al., 2016). }\end{array}$ \\
\hline White spotting & $\begin{array}{l}\text { A phenotype resulting from impairment of migration } \\
\text { and/or differentiation of melanocytes or their } \\
\text { precursors, causing patchy regions of white tissue. } \\
\text { Differentiated from amelanism through molecular } \\
\text { mechanism rather than visual appearance. }\end{array}$ & 52 & $\begin{array}{l}\text { White spotting phenotypes in } \\
\text { domestic horses are } \\
\text { associated with a large } \\
\text { number of distinct mutations } \\
\text { identified in KIT (Haase et al., } \\
\text { 2015). }\end{array}$ \\
\hline \multicolumn{4}{|c|}{ Colour shift versus pattern alteration } \\
\hline Colour shift & $\begin{array}{l}\text { Any phenotype in which organismal colour shifts } \\
\text { either locally or globally, without impacting the } \\
\text { spatial boundaries of its existing patterning. } \\
\text { Includes phenotypes in which an organism's } \\
\text { existing pattern is overridden, e.g. whole body } \\
\text { eumelanism. }\end{array}$ & 164 & $\begin{array}{l}\text { In Japanese quail, a } \\
\text { frameshift deletion in ASIP is } \\
\text { associated with the recessive } \\
\text { black phenotype, in which } \\
\text { feather colour is darkened } \\
\text { across the whole body without } \\
\text { altering pattern boundaries } \\
\text { (Hiragaki et al., 2008). }\end{array}$ \\
\hline Pattern alteration & $\begin{array}{l}\text { Any phenotype in which the spatial boundaries of } \\
\text { an organism's colour pattern change, including the } \\
\text { formation of new boundaries e.g. establishment of } \\
\text { a pattern in a previously uniform region. Does not } \\
\text { include phenotypes in which an existing pattern } \\
\text { changes colour without change to the pattern } \\
\text { boundary. }\end{array}$ & 99 & $\begin{array}{l}\text { The convergent evolution of } \\
\text { horizontal melanic stripes in } \\
\text { different cichlid species is } \\
\text { associated with regulatory } \\
\text { changes in agouti-related } \\
\text { peptide 2, and expression } \\
\text { levels are predictive of stripe } \\
\text { presence across multiple } \\
\text { cichlid radiations (Kratochwil } \\
\text { et al., 2018). }\end{array}$ \\
\hline
\end{tabular}

389 In every category except changes in carotenoid pigmentation, coding sequence changes were 390 the most prevalent (Figure 4A). The categories with the lowest cis-regulatory proportion were 391 loss of carotenoid colouration (0\%), and amelanism (4.8\%). Although loss of carotenoid colouration had too few entries (only 2 ) to draw definitive conclusions, it is notable that both 
393

categories represent a loss of pigmentation. In contrast, the other five categories represent either changes in relative pigment quantity or impairment of cell migration. The prevalence of coding mutations amongst phenotypes involving pigment loss is largely due to loss-of-function mutations affecting genes vital for carotenoid processing or melanin biosynthesis, respectively. Thus, these results support the hypothesis that phenotypes involving changes to pigmentation quantity or distribution are associated with a higher proportion of cis-regulatory mutations than loss phenotypes.

Both phenotype categories pertaining to carotenoid colouration had relatively few entries - six for change in carotenoid colouration (all of which were cis-regulatory) and two for loss of carotenoid colouration. However, both categories combined did have a high cis-regulatory proportion $(75.0 \%)$ suggesting that carotenoid pigmentation evolution may be more driven by cis-regulatory changes compared with melanic pigmentation. The overall cis-regulatory proportion for melanic pigmentation was $17.7 \%$. Further studies investigating carotenoid phenotypes would be invaluable in determining whether carotenoid colouration does evolve through different mutation types.

For melanic pigmentation, the category with the highest cis-regulatory proportion was white spotting $(26.9 \%)$, and this was the only melanin-related category with a higher proportion than the average. Amelanism (4.8\%) had the lowest proportion, and the remaining categories pheomelanism $(16.4 \%)$, dilution $(15.0 \%)$, and eumelanism $(11.3 \%)$ were all similar to the average. Notably, two phenotype categories were strongly associated with domesticated entries - 18 out of 20 dilution entries, and all of the 52 white spotting entries, were identified in domesticated taxa (Figure S3). White spotting phenotypes are associated with highly pleiotropic effects, with many white spotting entries in Gephebase being deleterious in the homozygous state. It is therefore not surprising that white spotting mutations were only identified in domesticated taxa, where they can be subject to heterozygous advantage (Hanly et al., 2021; Hedrick, 2015). The slightly higher cis-regulatory proportion of this category may reflect the nature of white spotting phenotypes, which result from impairment of pigment cell migration or differentiation. It is therefore possible that coding mutations that would cause white spotting are more likely to be non-viable due to their pleiotropic effects on upstream cellular development.

Finally, phenotypes relating to changes in pigment pattern boundaries had a higher cisregulatory proportion $(29.3 \%)$ than phenotypes relating to colour shifts $(10.4 \%)$. This was also true for every study methodology and taxonomic status (Figure S3 and S4). However, notably this difference between colour and pattern phenotypes was more pronounced in nondomesticated studies - for intraspecific and interspecific entries pattern phenotypes had a cis- 
regulatory proportion of $60 \%$ compared with $14.3 \%$ for colour (Figure S3). This is in spite of white spotting phenotypes being exclusively domesticated as well as exclusively categorised as pattern alterations. Thus, the disparity between colour and pattern phenotypes in terms of mutation type may be larger than this dataset suggests in non-domesticated evolution, particularly given the overall prevalence of domesticated studies in pigmentation research. Overall the Gephebase dataset supports a disproportionate role of cis-regulatory changes in the generation of pattern variation (Orteu and Jiggins, 2020).

Upstream developmental processes are associated with a higher proportion of cisregulatory mutations

Differences in mutation proportions may also be associated with the developmental or cellular function fulfilled by the gene in question. We hypothesise that genes associated with upstream developmental processes would exhibit different proportions to those associated with downstream processes. For example, genes that play a role in cellular differentiation (upstream process) may be less tolerant of coding sequence mutation than genes contributing only to pigment deposition (downstream process). To test this, we assigned each gene to only one of six categories reflecting different cellular and/or developmental processes (Table 3). Three of these categories are cell type-specific functions such as melanosome formation, pigment biosynthesis and pigment trafficking/localisation. The remaining categories included more upstream functions such as pigment cell development, differentiation and cellular interactions (Table 3).

As predicted, the three categories representing more upstream cellular/developmental processes - pigment cell differentiation, pigment cell development and cellular interactions were all associated with a higher proportion of cis-regulatory mutations than categories representing downstream cellular functions (Figure 4B). Only 2 entries fit the criteria for the cellular interactions category, both of which implicate cis-regulatory changes (Figure 4B). This small number of entries makes it difficult to determine whether differences in cellular interactions are associated with different mutation proportions - more data entries would be needed for conclusions to be drawn. Alternatively, the categories representing downstream processes - melanosome formation, pigment biosynthesis and pigment trafficking/localisation - all exhibited a higher proportion of protein coding mutations. The overall trend appears to fit the hypothesis that for upstream processes such as pigment cell lineage specification, mutations are more likely to be cis-regulatory when compared with downstream cellular processes which do not affect cell viability, such as variable rates of pigment deposition. 
Table 3: Summary of functional categories: assignment criteria for each functional category, and the total number of entries in the dataset for which that category was assigned.

465 Each gene was assigned to only one functional category.

\begin{tabular}{|l|l|l|l|}
\hline Category Name & Criteria for Assignment & $\begin{array}{l}\text { Number of } \\
\text { Unique Genes }\end{array}$ & $\begin{array}{l}\text { Number of } \\
\text { Entries }\end{array}$ \\
\hline $\begin{array}{l}\text { Pigment cell } \\
\text { differentiation }\end{array}$ & $\begin{array}{l}\text { Contributes to determining fate specification of pigment } \\
\text { cell precursors }\end{array}$ & 8 & 15 \\
\hline $\begin{array}{l}\text { Pigment cell } \\
\text { development }\end{array}$ & $\begin{array}{l}\text { Necessary for full development of pigment cells post- } \\
\text { specification }\end{array}$ & 10 & 24 \\
\hline $\begin{array}{l}\text { Cellular } \\
\text { interactions }\end{array}$ & $\begin{array}{l}\text { Involved in signalling or other cellular interactions, } \\
\text { either between or within pigment cell classes }\end{array}$ & 2 & 2 \\
\hline $\begin{array}{l}\text { Melanosome } \\
\text { formation }\end{array}$ & $\begin{array}{l}\text { Contributes to the formation or maintenance of } \\
\text { melanosomes, specialised melanin vesicles }\end{array}$ & 8 & 46 \\
\hline $\begin{array}{l}\text { Pigment } \\
\text { biosynthesis }\end{array}$ & $\begin{array}{l}\text { Role in directly synthesising or processing pigments or } \\
\text { their direct precursors }\end{array}$ & 25 & 253 \\
\hline $\begin{array}{l}\text { Pigment trafficking } \\
\text { localisation }\end{array}$ & Role in inter- or intracellular localisation of pigments, & 4 & 16 \\
\hline
\end{tabular}

DNA binding proteins are associated with a higher proportion of cis-regulatory mutations than other molecular functions

470 We were also interested in whether the specific molecular activity of a gene would influence 471 the distribution of mutation types. Coding mutations are constrained by the degree of 472 functional conservation required by the protein's molecular function. Transcription factors 473 implicated in multiple regulatory functions may be more constrained than enzymes that 474 catalyse pigment-specific pathways, as even loss-of-function mutations may be tolerated in 475 enzymes that are functionally specialised and non-essential (Pál et al., 2006). For example, 476 differential expression of the transcription factor sox10 resulting from cis-regulatory mutations 477 underlies changes to melanogenesis in both pigeons and chickens (Domyan et al., 2014; 478 Gunnarsson et al., 2011). Sox10, and other sox family transcription factors, are highly 479 pleiotropic and essential for neural crest specification, migration and differentiation (Sarkar 480 and Hochedlinger, 2013). No sox10 coding mutations were identified in this dataset. 481 Conversely, multiple presumptive null coding mutations have been identified in $m c 1 r$, including 
one example of parallel evolution in cavefish. Thus, in contrast to sox10 and other transcription factors, highly specialised proteins such as mc1r may be less susceptible to pleiotropy arising from null mutations. As such, we expected that molecular functions that are less pleiotropic would exhibit higher cis-regulatory proportions, and vice versa.

Using EBI's QuickGO mouse slimmer and manual combination of highly related molecular GO terms, we assigned each entry to one of 7 categories of GO molecular function (see Methods, Table S1, Figure S4A and S4B). We then examined the mutation proportions for each GO category (Figure 4C). DNA binding had the highest cis-regulatory proportion of any category $(61.5 \%)$ and was the only category with a majority of cis-regulatory mutations. Signaling receptor binding had a higher than average cis-regulatory proportion of $42.9 \%$, but conversely signaling receptor activity had the lowest with $6.0 \%$. Protein binding also exhibited a higher than average cis-regulatory proportion (27.3\%). Taken together, these results indicate that the ability of Transcription factors to evolve phenotypically-causal coding variants is limited by their pleiotropic roles in development, while their non-coding regions offer a more viable path for phenotypic changes.

An interesting result is that ligands ("signaling receptor binding") shows a higher cis-regulatory proportion than receptors ("signaling receptor activity"). For most signaling receptor genes, the corresponding ligand was also present in the dataset in the signaling receptor binding GO category. This includes kit and its ligand, as well as multiple endothelin signaling receptors and their respective ligands. Our results suggest that the coding sequence of genes encoding signaling ligands are more constrained than that of their signaling receptors. This supports previous findings that cis-regulatory mutations in ligand genes drive morphological evolution (Martin and Courtier-Orgogozo, 2017). The receptor/ligand pairing with the most entries in the dataset, mc1r/asip, supports this - mc1r has a cis-regulatory proportion of $1.1 \%$, in contrast with its ligand asip with $39.4 \%$. This trend is also observed when candidate gene studies are removed, with $5.5 \%$ of cis-regulatory mutations for $m c 1 r$ and $50 \%$ of cis-regulatory changes for asip. A similar example, albeit with fewer entries, is kit/kitlg. Kit has a cis-regulatory proportion of $17.5 \%$ ( 7 out of $40,23 \%$ if candidate gene studies are excluded), and multiple putative null mutations. Although kitlg has only four entries, all uncovered by linkage mapping or association mapping, three are cis-regulatory. Both the low number of kitlg entries and its relatively higher cis-regulatory proportion may indicate a lower evolutionary tolerance of coding mutations when compared with its receptor. Overall, our results indicate that ligands may be more vulnerable to pleiotropy than their corresponding receptors, or that ligand mutations preferentially drive localised pigmentation evolution compared with receptor mutations. It has been suggested that ligands play a specific role in altering spatially localised phenotypes due to the specificity of their expression patterns - in contrast to their 
518 corresponding receptors, which are more likely to be ubiquitously expressed (Martin and 519 Courtier-Orgogozo, 2017). Additionally, it may be expected that only the ligand-binding 520 domains of receptor proteins are highly constrained by specificity, where other functional

521 domains are more able to tolerate mutations (Worth et al., 2009). Taken together, both the 522 modularity associated with ligand expression patterns as well as the greater number of 523 mutation-tolerant domains in receptors may explain the higher cis-regulatory proportion in 524 ligand encoding genes compared to receptor genes. 
A

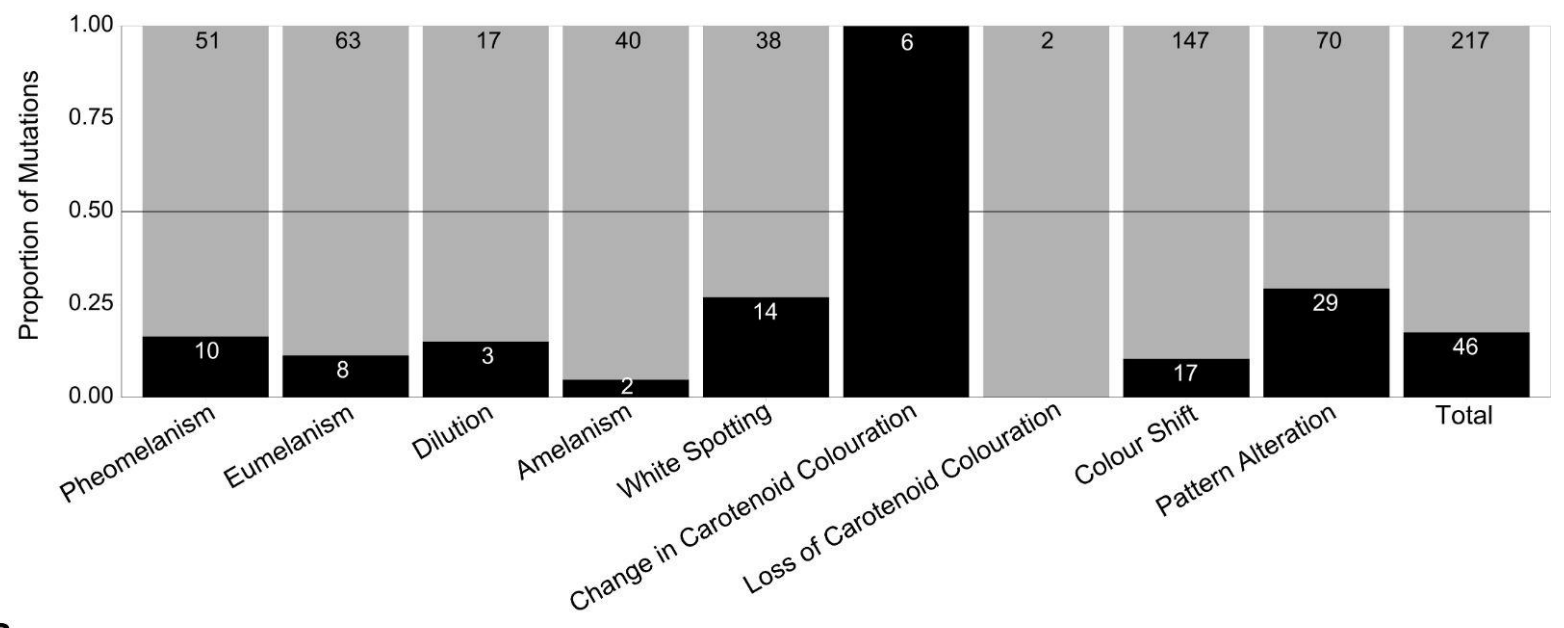

B

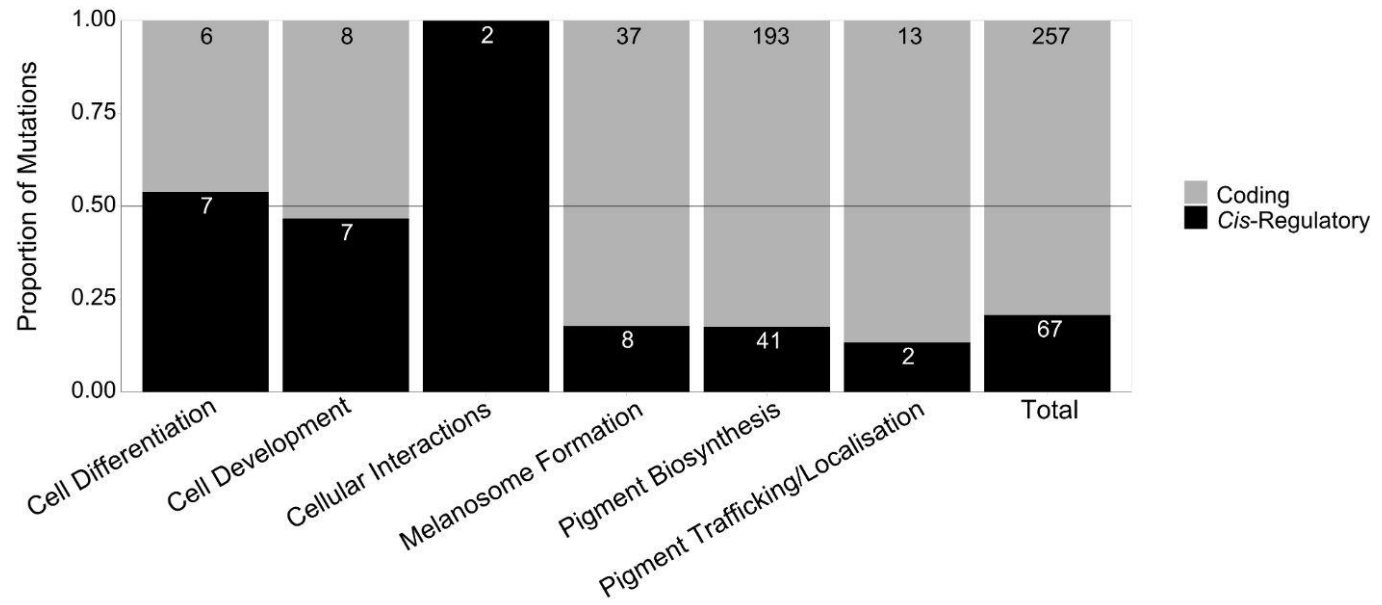

C

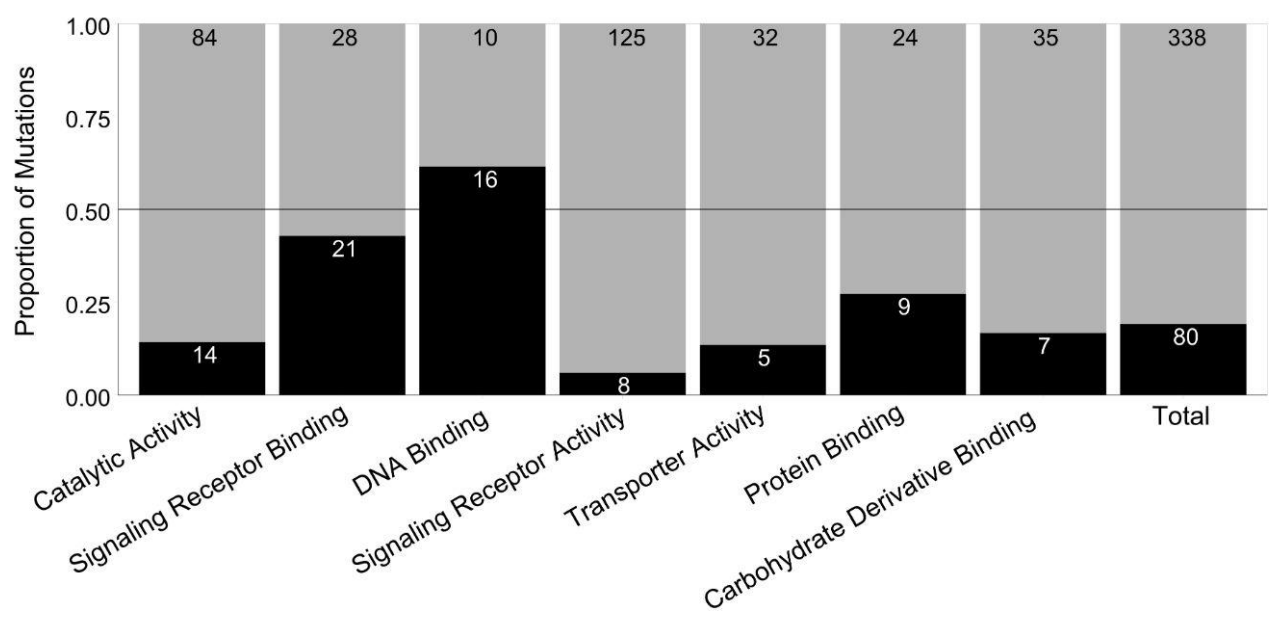

526 Figure 4. A: The proportion of cis-regulatory and coding mutations associated with each

527 phenotype category, as well as the total proportions of the dataset. Note that the total 528 proportions were for all entries that were assigned to either colour shift or pattern alteration.

529 B: The proportions of cis-regulatory and coding mutations associated with each cellular 530 function category. C: The proportion of cis-regulatory and coding mutations associated with 
each parent gene ontology assignment. The numbers within each bar represent the number of entries in that category. The grey horizontal line is at 0.5 .

533

\section{Divergent pigmentation systems have fewer shared evolutionary hotspots}

535 One of the major outcomes of the study of the genetic basis of evolutionary change is the 536 discovery that the repeated co-option of the same genes underlies the evolution of convergent 537 phenotypes. Genes that are repeatedly found as causal drivers of similar phenotypic changes 538 in diverse taxa or populations have been referred to as genetic hotspots (Martin and 539 Orgogozo, 2013). Here, we hypothesised that similar pigmentation systems would be more 540 likely to evolve through re-use of the same set of genes, whereas more divergent pigmentation 541 systems would have fewer shared evolutionary hotspots. We therefore divided the dataset by 542 clade and compared the genes shared between each pairing of clades. The overlap between 543 clades was calculated by combining the entries corresponding to each shared gene, and 544 normalising by the total number of entries in the respective clade (see Methods).

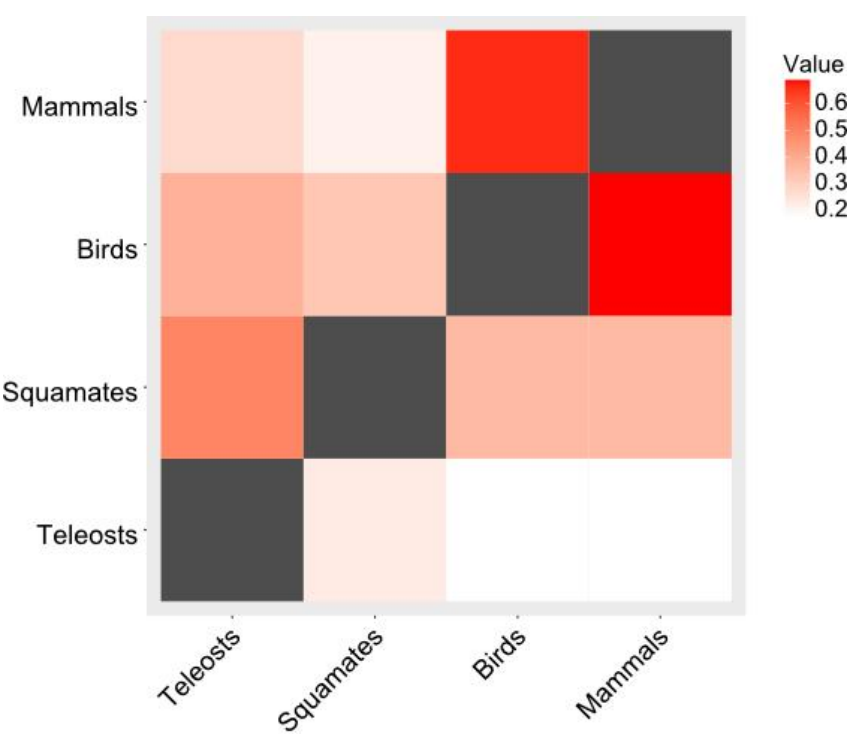

547 Figure 5. Heatmap of the normalised entries associated with genes shared between each 548 clade pairing. For instance, the top left square has a value equal to the number of mammalian 549 entries for genes that were also identified in teleost studies, divided by the total number of 550 mammalian entries.

552 When comparing pigmentation systems with multiple pigment cell classes (teleosts and 553 squamates) to those with only one (birds and mammals), each clade exhibited the greatest 
554 hotspot overlap with the clade with which it shares a pigmentation system (Figure 5). The two

555 largest normalised values were in mammalian entries for genes shared with birds, and in bird

556 entries for genes shared with mammals. Likewise both teleosts and squamates had the

557 greatest overlap with one another. Additionally, there was considerable overlap between

558 squamates and birds which may reflect their phylogenetic relationship. As the number of

559 shared hotspot genes would be expected to reduce over evolutionary time, phylogenetic

560 distance is likely to contribute to the observed overlap between clades (Conte et al., 2012).

561 Although $m c 1 r$ was highly represented in all clades, and thus contributed considerable hotspot

562 overlap to all clade pairings, many other genes that were highly represented in the dataset

563 were confined to mammals and birds only. The second, third, and fourth most represented

564 genes in the overall dataset - kit, asip, and tyrp1 - all had no teleost or squamate entries, and

565 are all implicated in melanogenesis or melanogenic switching. However, certain melanogenic

566 genes also exhibited overlap between teleost and squamate entries, such as oca2, a

567 melanosomal transport protein (Table S2). Oca2 comprised 15\% ( $n=3)$ of all teleost entries,

568 and $12.5 \%(n=1)$ of squamate entries - in contrast being rare in mammals $(0.82 \%, n=2)$ and

569 absent entirely in birds. Only one non-melanic pigmentation gene was shared between birds

570 and squamates. Aside from $m c 1 r$, no single gene was identified in all four clades.

571 Overall, the observed trend of higher hotspot overlap between the most similar pigmentation

572 systems was as expected, and may indicate shared genetic mechanisms underlying pigment

573 evolution in systems with or without multiple pigment cell classes. The low number of non-

574 melanic pigmentation entries (only 22 in total) makes it difficult to draw conclusions about the

575 relevance of hotspot genes outside of melanogenic pathways for clades with additional 576 pigment types. 


\section{Discussion}

578 Gephebase is a powerful tool that can be used to compile data on phenotype-genotype 579 associations to infer general patterns regarding the mechanisms underlying evolutionary 580 change. Importantly, this dataset can be used to find knowledge gaps in the current literature, 581 and identify novel directions and study systems for future research. Here, we analysed a large 582 dataset of 363 Gephebase entries, each a pair of alleles linked to phenotypic variation in 583 vertebrate pigmentation. Of the three forms of empirical evidence accepted by Gephebase, it 584 was clear that the study methodology with higher ascertainment bias - candidate gene 585 approach - identified more coding sequence mutations than the other methods. Irrespective 586 of this bias, protein coding changes were still the majority of mutations identified with linkage 587 and association mapping. In addition, we did identify several factors that may affect the relative 588 distribution of coding and cis-regulatory mutations. Below we discuss these factors and 589 highlight new avenues of research in the vertebrate pigmentation field.

591 Strong selection pressure might explain the higher proportion of coding mutations associated with vertebrate pigmentation diversity

593 We found that vertebrate pigmentation overall, and in domesticated species in particular, is associated with a majority of coding mutations. In the case of domesticated vertebrates, this may be explained by the strong selective pressure of the domestication process. During any form of artificial selection, desirable traits will be under strong directional selection, which can overcome the negative pleiotropic effects of coding mutations. Such an example is that of frame overo horses, where changes in patterning are a result of heterozygosity for a coding mutation in endothelin B receptor (ednrb), which leads to a white spotted pattern (Metallinos

600 et al., 1998). Homozygosity for this mutation leads to lethal white foal syndrome - affected 601 foals are completely white, and die shortly after birth. Selection for white spotted patterns in 602 domestic horses has thus led to a lethal deleterious coding mutation becoming prevalent in 603 the population, whereas in wild populations such a mutation would likely not have conferred 604 sufficient advantage to overcome its negative pleiotropy.

605 A sufficiently strong selection pressure may likewise allow the emergence of pleiotropic coding 606 mutations in wild populations. Gephebase contains examples that demonstrate how rapidly changes in pigmentation patterns may evolve when under such pressures, particularly in the context of retaining cryptic camouflage against a new or rapidly changing environment. For 609 instance, populations of North American deer mice exhibit high gene flow, and thus low 610 population structure, with the exception of the agouti locus. Strong selection for crypsis against 
611 variable soil colouration instead leads to high variance in agouti coding sequence, and rapid

612 divergence driven by colonisation over the last $\sim 4000$ years (Pfeifer et al., 2018). The

613 prevalence of intraspecific coding mutations in our dataset may therefore be related to the

614 strength of selection typical for vertebrate pigmentation evolution. In the future it would be

615 interesting to investigate the effect of relative selection strength on the role of each mutation

616 type, and to perform the same analyses in multiple morphological traits to determine if these

617 trends are pigmentation specific.

618

\section{Evolutionary timescales and taxonomic distance}

620 We found that shorter taxonomic distances (domesticated and intraspecific entries) are 621 associated with a higher proportion of protein coding changes than interspecific changes. 622 These results should be taken with caution as the sparsity of interspecific studies indicates comparatively little investigation of pigmentation traits across larger evolutionary timescales. Interestingly, the majority (8 out of 14 ) of interspecific entries were identified in teleost species, despite their overall underrepresentation in the dataset. Further, 6 of these interspecific entries were found in East African cichlids. The current overrepresentation of shorter evolutionary timescales may introduce bias in the types of mutation that can be identified. Shorter evolutionary timescales may allow for pleiotropic mutations, as well as mutations that confer an advantage only in a specific environmental context. As such, the higher number of intraspecific and domesticated case studies is likely to result in overrepresentation of coding mutations. Expanding the timescales investigated in pigmentation evolution will facilitate testing of this hypothesis, and a greater understanding of how pigmentation changes over evolutionary time.

Identifying bird and mammal model systems for interspecific studies is challenging owing to the often-limited potential for hybridisation, restricting the types of mapping techniques available. For instance, the only two interspecific mammalian entries examined differences within the black rat species complex, and between the house mouse and tobacco mouse, respectively (Kambe et al., 2011; Robbins et al., 1993). Both of these studies used a candidate gene approach. In birds, Toews et al. used an association mapping approach to examine pigmentation evolution in two naturally hybridising species of warbler with highly divergent pigment patterns (Toews et al., 2016). Diversification of model systems may facilitate a greater 


\section{Potential biases introduced by study systems}

646 Mammalian and avian systems dominate the majority of the entries. These only possess

647 melanocytes as pigment cells, and pigmentation differences primarily result from spatial and

648 temporal differences in pigment production and deposition. In other vertebrates, pigmentation

649 patterns result from the presence and differential arrangement of different classes of pigment

650 cells that share a developmental origin. Those few studies in the Gephebase dataset that

651 focus on clades with distinct chromatophore classes often found novel pigmentation

652 phenotypes associated with a wider range of genes. This is also corroborated by the greater

653 numbers of shared hotspot genes between clades with similar pigmentation systems - the

654 genes identified in teleost and squamate studies showed little overlap with those found in

655 mammals and birds. Studies in clades with distinct chromatophore classes also implicated

656 more regulatory mutations than average. As current research continues to contribute new

657 case studies, it will be interesting to look into whether this trend is borne out, or whether the

658 higher prevalence of cis-regulatory mutations is an artefact of a low number of studies focusing

659 on organisms with multiple pigment cell classes. In either case, greater emphasis on a broader

660 set of model systems will benefit our broad understanding of vertebrate pigmentation

661 evolution.

662 In particular it would be of interest to expand the number of studies in teleosts and reptiles to 663 validate the hypothesis that pigmentation systems with multiple chromatophore classes evolve 664 preferentially through cis-regulatory modifications. Similarly, amphibian pigmentation 665 evolution was only represented by one study. Amphibians' highly permeable skin and lack of 666 epidermal protection, as well as their commonly biphasic aquatic and terrestrial life cycles, 667 may necessitate distinct adaptive functions for colouration compared with other vertebrate 668 clades (Rudh and Qvarnström, 2013). These underrepresented clades will be highly 669 informative, particularly with respect to interactions between chromatophore classes and 670 pattern formation.

672 The importance of understanding the cellular and developmental basis of variation

673 We found that changes in patterning had a higher cis-regulatory proportion than changes in 674 colour. This is consistent with previous hypotheses that cis-regulatory mutations largely 675 govern spatial changes due to altering expression patterns (Carroll, 2008). For example, in 676 sticklebacks a cis-regulatory allele of the kit ligand gene reduces its specific expression in gill 677 tissue, leading to divergent gill pigmentation phenotypes (Miller et al., 2007). Gephebase 
678 gathers several such examples, where mutations in widely expressed genes are cis679 regulatory, so that only the expression in specific tissues is affected.

680 Nonetheless, the majority of pattern alteration case studies involve coding mutations. When 681 looking more closely at some of these, we realised that many are in fact loss-of-function 682 mutations in genes that are expressed only in specific regions of the body. For instance, the 683 urucum breed of canary exhibits a red bill and legs, which are yellow in wild type canaries 684 (Gazda et al., 2020). This is the result of a mutation that compromises the enzymatic activity 685 of $\mathrm{BCO} 2$, an enzyme responsible for breakdown of full-length red carotenoids into shorter apocarotenoids. The specificity of this allele in affecting the bill and the legs is the result of loss-of-function mutations in a gene whose expression was already restricted to specific tissues.

Without knowing the expression patterns and the level of pleiotropy of a given gene, we may be wrongly categorising phenotypes as pattern alterations when in fact they are colour shifts. Unfortunately, we have no way of testing this, since most case studies focus solely on the genotype-phenotype association without conducting gene expression or developmental studies. Knowledge of a gene's specific function, together with its placement in a cellular and developmental context, is essential for an understanding of when and how certain genes and mutations are favoured over others.

696 Characterising trait development at the gene expression and cellular level is ever more 697 important since we found different mutation proportions associated with differences in the upstream or downstream position of cellular and developmental processes. The genes contributing to upstream processes, i.e. those related to cellular differentiation and development, were more likely to be cis-regulatory compared with downstream processes. $\mathrm{A}$ previous study (Stern and Orgogozo 2008 Evolution, Table 3) distinguished two categories of genes, the ones that act at or near the terminal points of regulatory networks, named differentiation gene batteries, and the ones that are upstream in the gene network, and found that the proportion of cis-regulatory mutations was not significantly different for the two categories. This analysis was based on a compilation of 331 mutations for all types of traits across animals and plants. It is possible that this previous categorization was erroneous as it encompassed very diverse gene networks. Here, by focusing on vertebrate pigmentation, we performed a more robust assignment of the upstream versus downstream gene network position and uncovered an effect on the proportion of cis-regulatory mutations.

710 One of these studies identified a cis-regulatory mutation that altered the expression of colony 711 stimulating factor 1 (csf1), a signalling factor expressed in xanthophores that is required for 712 their differentiation and survival (Patterson et al., 2014). In Danio albolineatus, a close 
713 relative of the zebrafish $D$. rerio, increased expression via a cis-regulatory mutation of csf1a

714 was associated with early xanthophore recruitment (Patterson et al., 2014). The precocious

715 xanthophore appearance led to changes in abundance and distribution of all three principal

716 chromatophore classes (melanophores, xanthophores, and iridophores) which ultimately

717 inhibited formation of the stripe pattern found in other Danio species. This study illustrates

718 the potential complexity of phenotypes arising from mutations that affect cellular interactions.

719 The relative lack of studies that have identified such mutations represents an exciting

720 avenue for future pigmentation evolution research.

721 In contrast, coding mutations in more downstream categories would typically be expected to 722 have lower impact on non-pigmentation phenotype. One study found that a loss-of-function 723 mutation in scavenger receptor B1 (SCARB1) in canaries produces a completely white 724 phenotype due to SCARB1 being necessary for carotenoid uptake. As a result of SCARB1's 725 specialised role, this null coding mutation produces a spectacular pigmentation phenotype 726 (Toomey et al., 2017). These results support the hypothesis that developmentally upstream 727 genes may be constrained by pleiotropy. Given the overrepresentation of pigment synthesis 728 case studies in the vertebrate pigmentation dataset, the collection of more data regarding other types of trait variation is imperative.

730

\section{What are the main knowledge gaps?}

732 Most of the vertebrate pigmentation entries (341 out of 363) result from the study of variation 733 in melanic traits. In contrast, variation in other types of colour traits, such as carotenoids and 734 pteridines, structural colouration, and colour plasticity remain largely unexplored. Further, most case studies address naturally selected traits with a relatively simple genetic basis - and only 20 out of 363 entries assessed variable sexually dimorphic traits. It would therefore be interesting to test if the same findings hold true for sexually selected traits or highly polygenic traits where each mutation has a small effect size.

739 The benefits of broadening the nature of the focal trait are manifold, but an obvious one is that

740 by focusing on unexplored traits we may find previously uncharacterised genes underlying 741 these traits. For example, the study of variation in yellow pigmentation in budgerigar parrots 742 led to the identification of a coding mutation in a previously uncharacterised polyketide 743 synthase that is involved in the synthesis of yellow polyene pigments called psittacofulvins 744 (Cooke et al., 2017).

745 We found only one entry in the dataset relating to cellular structural colouration, an 746 interspecific study investigating pigment pattern differences between two Danio fish species. 

with a cis-regulatory mutation in the Endothelin-3 (Edn3) signaling peptide (Spiewak et al., 2018). Edn3 promotes iridophore proliferation, this cis-mutation leads to decreased Edn3 expression and correspondingly lower iridophore complement in D. nigrofasciatus. A lower number of iridophores secondarily affects melanophore proliferation, leading to a reduction of both cell types and disruption of the defined striped pattern in D. nigrofasciatus. This study being the only one in Gephebase relating to structural variation highlights that structural colouration is relatively unexplored, and represents an emerging field of research where new genes and developmental processes leading to variation in cells and physical structures will be identified.

The current entries in Gephebase are heavily focused on colouration traits that are genetically determined independently of environmental variables. Colour variation can also arise as a result of phenotypic plasticity, where the same genotype will generate different colour states under different conditions. Six entries pertained to plastic or seasonal colour changes - for instance, cis-regulatory alleles of Asip determine whether the winter coat of snowshoe hares is brown or white (Jones et al., 2018). Determining how plasticity emerges and evolves remains a challenge. Genes involved in plasticity evolution can only be identified when mapping differences between closely related species or populations which show variation in the presence and absence of plastic colouration (Gibert, 2017). Likewise variation in plastic colour responses can only be mapped by measuring variation in populational reaction norms, which are costly and time consuming experiments. Nonetheless, such studies will be key to discern between the two main hypotheses regarding the evolution of plasticity - whether evolutionary change occurs through changes in genes that sense and regulate a downstream response to external factors, or instead through changes in the colouration genes themselves that become responsive to environmental cues.

Sexually selected traits are also underrepresented in the database, making up only $5.5 \%$ of the case studies. Understanding the interplay between natural and sexual selection on colour traits is important, since they may often act in opposite directions. For example, in several species of Lake Malawi cichlids a well camouflaged colour morph is associated with a cisregulatory mutation in pax7. However, this mutation also has a deleterious effect in that it disrupts male nuptial colouration. This conflict has been resolved by the invasion of a novel sex determination locus in tight linkage with the pax7 allele (Roberts et al., 2009). The importance of pigmentation patterns in mate choice can lead to such conflicts, and the ways in which they are resolved can present fascinating case studies. Sexually selected traits also present a conundrum in that it is unclear why and how trait variation is maintained in natural 
competition (Chenoweth and McGuigan, 2010). Identifying genes and genomic regions contributing to trait variation and studying its adaptive significance in wild populations creates the opportunity to understand this paradox (Johnston et al., 2013).

786 Finally, the Gephebase dataset is currently biased towards large-effect loci, as linkage mapping is limited in its statistical power to detect small effect mutations and polygenic architectures (Rockman, 2012; Slate, 2013). Association studies conducted on thousands of samples are now reaching a point where small-effect loci are detectable, under the conditions that these variants are common : for instance, several GWAS studies of skin pigmentation levels have uncovered an amino-acid polymorphism of MFSD12 as a determinant of colour variation across several continents (Adhikari et al., 2019; Crawford et al., 2017; Feng et al., 2021; Lona-Durazo et al., 2019). This gene is now a candidate that is also showing association signals in domestic animal studies (Hédan et al., 2019; Tanaka et al., 2019), suggesting it is effectively a hotspot of pigment variation. While human GWAS studies are systematically curated and will undoubtedly lead to powerful meta-analyses (Buniello et al., 2019), and while infrastructure is being built to integrate these data with laboratory model systems (Shefchek et al., 2020), there is a lack of resources to compile data from evolutionary and bred gene-totrait relationships beyond these organisms. Gephebase, OMIA, and Animal QTLdb (CourtierOrgogozo et al., 2020; Hu et al., 2021; Lenffer et al., 2006) are stopgap attempts at curating these data, but would need long-term resources to keep pace in front of increased rates of discovery in the genomic age.

803

\section{Conclusion}

805 As more of the genetic variants underlying trait variation are identified, it becomes possible to 806 more rigorously test predictions relating to the mechanisms of genetic evolution. Here, we

807 highlight some of the trends in vertebrate pigmentation evolution, and specifically test some 808 of the predictions made about the relative frequencies of cis-regulatory and coding mutations. 809 In contrast to many people's expectations, we found that the majority of the documented 810 variation in pigmentation is driven by coding sequence mutations. However, we also identified 811 multiple factors associated with mutational proportion that partly explain this disparity. We 812 therefore made suggestions for the future direction of vertebrate pigmentation research with 813 respect to both systems and study design. As the number and variety of case studies 814 continues to increase, we expect our understanding of the genetic, cellular and developmental 815 mechanisms underlying the evolution of vertebrate pigmentation to expand. 
Methods

\section{Literature curation in Gephebase}

818 Gephebase compiles pairs of alleles in association with pairs of phenotypic states (a genetic

819 variation causing a phenotypic variation is called a "gephe" for brevity). A full description of

820 the database is provided in (Courtier-Orgogozo et al., 2020). In short, data currently cover all

821 eukaryotes with relevant publications, with a focus on traits of evolutionary rather than clinical 822 relevance. This includes variations that have been artificially selected by breeders

823 ("Domesticated" dataset), or subject to experimental evolution under lab-controlled selective 824 pressures. Data is manually curated by a team of less than a dozen researchers, using 825 keywords as well as Pubmed/Google Scholar citations to identify newly published studies. 826 Our current triage system gives priority to gephes identified by forward genetics (QTL 827 mapping, GWAS) with a single-gene resolution and reasonable supporting evidence for 828 causality (if not for the variant, at least for the gene). Gephes identified by candidate gene 829 approaches without mapping are also included when there is additional functional evidence 830 for the causality of the mutation. Gephebase is up-to-date and gathers all relevant papers 831 published until 2017. Past 2017, data curation efforts have mainly focused on colour variation 832 in vertebrates (Gephebase "Trait" category = "Coloration"). The download of Gephebase data 833 on 28 October 2021 (Supplementary File 1), which was used for the present study, can be 834 considered as a compilation of the genes and mutations contributing to Vertebrate coloration 835 up to and including 2019.

\section{Meta-analyses}

838 To examine trends in colour pattern evolution, we utilised Gephebase as a resource for 839 exploring genotype-phenotype relationships. We formed a working dataset by selecting every

840 Gephebase entry pertaining to the trait category 'colouration', and further filtered those entries 841 by removing all entries pertaining to non-vertebrate species (accessed 28/10/2021). In total 842 we retrieved 363 entries, with each entry representing a mutation at a single locus. Each 843 mutation was present in only one gene for the organism in which it was identified, and there 844 were a total of 61 unique genes identified across 89 vertebrate species. For each entry, we 845 examined five parameters defined by Gephebase - Gene ID, Taxonomic Status, Study 846 Methodology, Aberration Type, and Molecular Type (Courtier-Orgogozo et al., 2020). We 847 further defined five additional parameters - Clade, Pigment Type, Phenotype Category, 848 Functional Category, and Protein Category (Supplementary File 1). 


\section{Assignment of new parameters}

851 Clade: Each vertebrate represented in the dataset unambiguously belonged to one of five clades with distinct pigmentation biology - amphibians, teleosts, squamates, birds and

853 mammals. As such, we divided entries into these clades to compare trends in their different

854 pigmentation systems.

855 Pigment Type: In total, five pigment types were represented in the dataset - biliverdin, 856 carotenoids, pteridines, melanins, and psittacofulvins. Additionally, one entry referred to structural coloration. Each entry could be unambiguously assigned to one or more of these categories. In total there were 10 entries in which a single genetic variant was associated with changes to multiple pigments. These entries were assigned to each relevant pigment type category.

Phenotype Category: We empirically assigned to each entry one of seven phenotype categories in order to group similar organismal phenotypes, and analyse trends in how they arise. Each entry was considered independently, and assigned the category that best describes the organismal phenotype based on the original study (Table 2). We accounted for both the visible phenotype in terms of pigment distribution and quantity, as well as the molecular mechanisms underlying the phenotype. For example, amelanism was distinguished from white spotting on the basis of whether the phenotype resulted from a lack of melanin synthesis, or a failure of melanocyte migration/differentiation. Ambiguous cases were not assigned a category - a total of 87 entries. This left a total of 276 assignments, of which 254 were cis-regulatory or coding. Additionally, categories were assigned relative to the ancestral state, so that for instance eumelanism refers to a mutation leading to an increase in eumelanin pigmentation.

873 We additionally assigned each category to either colour shift or pattern alteration, on the basis of whether the phenotype affected colour or spatial pattern boundaries. Each entry was considered independently, and these assignments were considered separately from the previous phenotype categories. Phenotypes involving a loss of patterning (for example whole body albinism resulting in no visible pattern boundaries) were considered colour shifts.

878 Ambiguous entries were not assigned a category - a total of 76 entries. This left a total of 287 879 assignments, of which 263 were cis-regulatory or coding. This total (263) was used for the 'total' bars in Figures 4A, S3, and S4.

881 Cellular Function Category: In order to analyse genes associated with different developmental and cellular roles, we assigned each gene in the dataset a functional category, reflecting its 
884 categories, these assignments were based on the gene rather than on individual entries.

885 Entries were assigned empirically, based on literature review of the genes identified by each 886 study, and the phenotypic function(s) they have been previously implicated in. As with 887 phenotype categories, each gene was assigned with high certainty and little ambiguity. 888 Additionally, a total of four genes, comprising seven entries, were removed for the purposes 889 of this analysis, as their cellular functions with regard to pigmentation biology specifically were 890 unclear. These were cyp19a1, copa, eif2s2, and Ivrn. Each gene had one entry each, except 891 for Ivrn, which had four entries.

Molecular Function Category: We assigned protein categories non-empirically by using the gene ontology (GO) terms associated with each gene in the dataset. We employed the EBI QuickGO Mouse Slimmer in order to identify parent GO terms associated with the sets of child terms associated with each gene. This slimmer was selected for being best representative of the distribution of GO terms within vertebrate clades. We then narrowed the set of GO terms to include only those associated with the 'Molecular Function' GO tree. We additionally manually combined a number of closely related GO terms in order to reduce the number of potential categories (Supplementary Table S1). In total there were 83 unique assignments of parent GO categories across the dataset. All of the 61 unique genes in the dataset generated at least one assignment, with the exception of mlana, a gene implicated in melanosome biogenesis. Mlana has only one molecular function assignment (GO:0005515 protein binding), which is not included in the QuickGO Mouse Slimmer. After combining closely related terms, there were 10 parent GO terms assigned. Then, we removed all categories with fewer than five unique gene assignments, of which there were three - RNA binding, enzyme regulator activity, and lipid binding. Thus we ended up with seven GO categories for comparison (Supplementary Table S1). The most commonly assigned GO category was the result of combining two GO terms - DNA binding and transcription factor activity. Although there are distinct biological differences between a gene displaying DNA binding activity and acting as a transcription factor, in the case of the Gephebase dataset there was nearly complete overlap between these terms. Only one gene was tagged as DNA binding without being tagged for

912 transcription factor activity, namely egfr - epidermal growth factor receptor. All other genes 913 were tagged with both GO terms, or neither.

914 Evolutionary Hotspots: We investigated the overlap of genes between pigmentation systems 915 by examining the number of entries corresponding to shared genes. For each clade, we looked 916 at all the genes identified in that clade, and then calculated the total number of entries 917 corresponding to those genes in each of the other three clades. We then normalised each of 918 these three figures by dividing by the total number of entries in that clade, in order to account 919 for the disparity in entries between clades. 


\section{Author contributions}

921 JE performed all data analysis. JE, MES, AM and VC contributed to the study design. MES,

922 AM and VC contributed to the gephebase curation. JE and MES wrote the manuscript with

923 contributions or feedback from all authors. All authors read and approved the final version of

924 the manuscript.

925

\section{Additional information}

927 Supplementary File 1 contains the Gephebase dataset downloaded on 28 October 2021. It

928 also contains information on parameter assignment (see methods) for each literature entry.

929

\section{Acknowledgments}

931 We thank members of the Morphological Evolution Lab for discussion. AM and VC were 932 supported by a John Templeton Foundation grant from 2014 to 2017 (JTF 43903). ES is 933 supported by a NERC IRF NE/R01504X/1.

934

935 Competing interests

936 The authors declare no competing interests. 
Figure S1

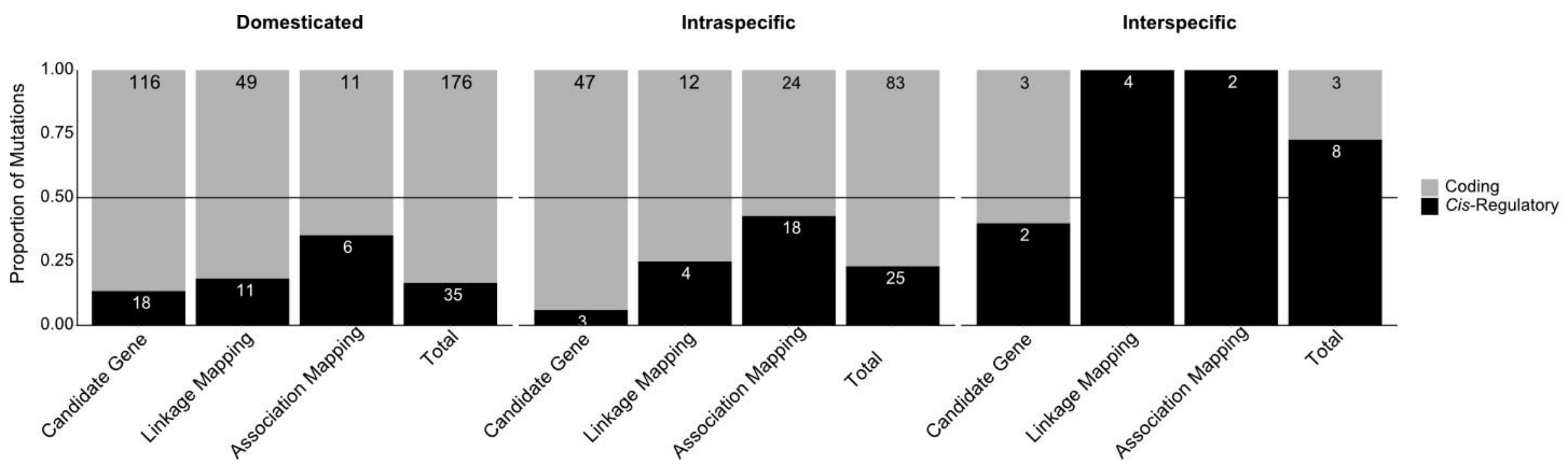

Figure S1 shows the proportion of cis-regulatory and coding mutations associated with different taxonomic statuses - domesticated,

943 intraspecific and interspecific variation - controlling for study methodology, as well as the total proportion for each taxonomic status. The numbers above each bar represent the number of entries in that category. The grey horizontal line is at 0.5 . 
946

Domesticated

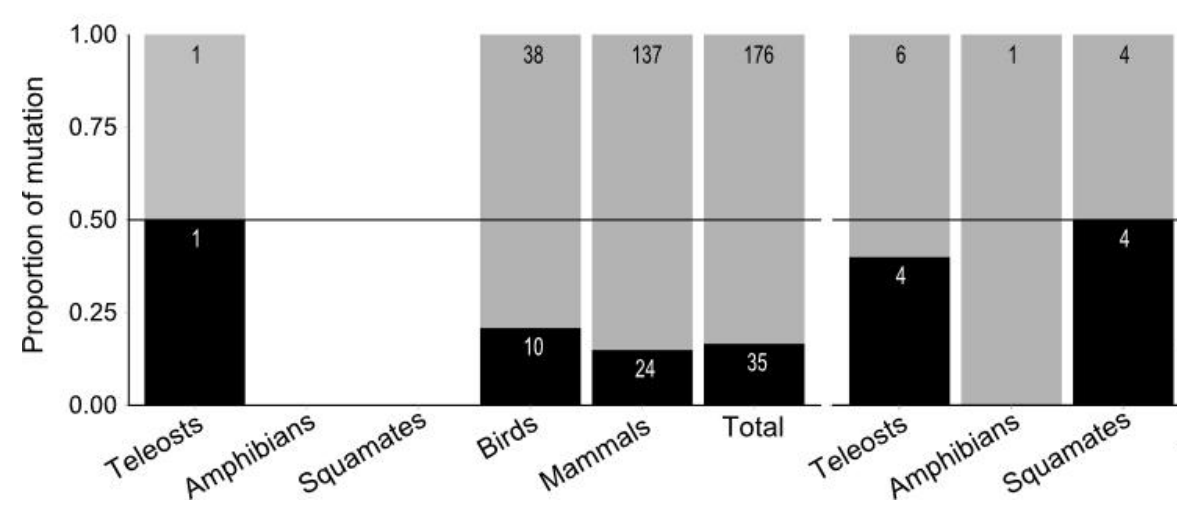

Intraspecific

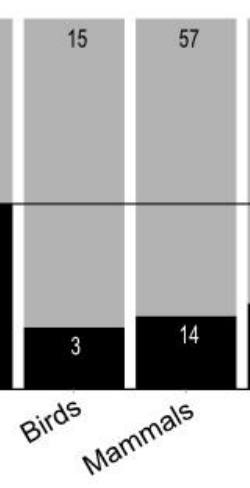

Interspecific

949 Figure $\mathbf{S 2}$ shows the proportion of cis-regulatory and coding mutations associated with different taxonomic statuses and clade - A:

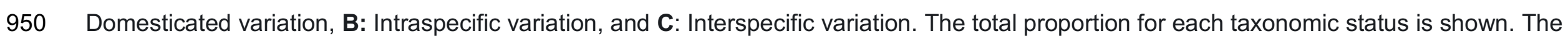
951 numbers above each bar represent the number of entries in that category. The grey horizontal line is at 0.5 . 
Figure S3

A Domesticated

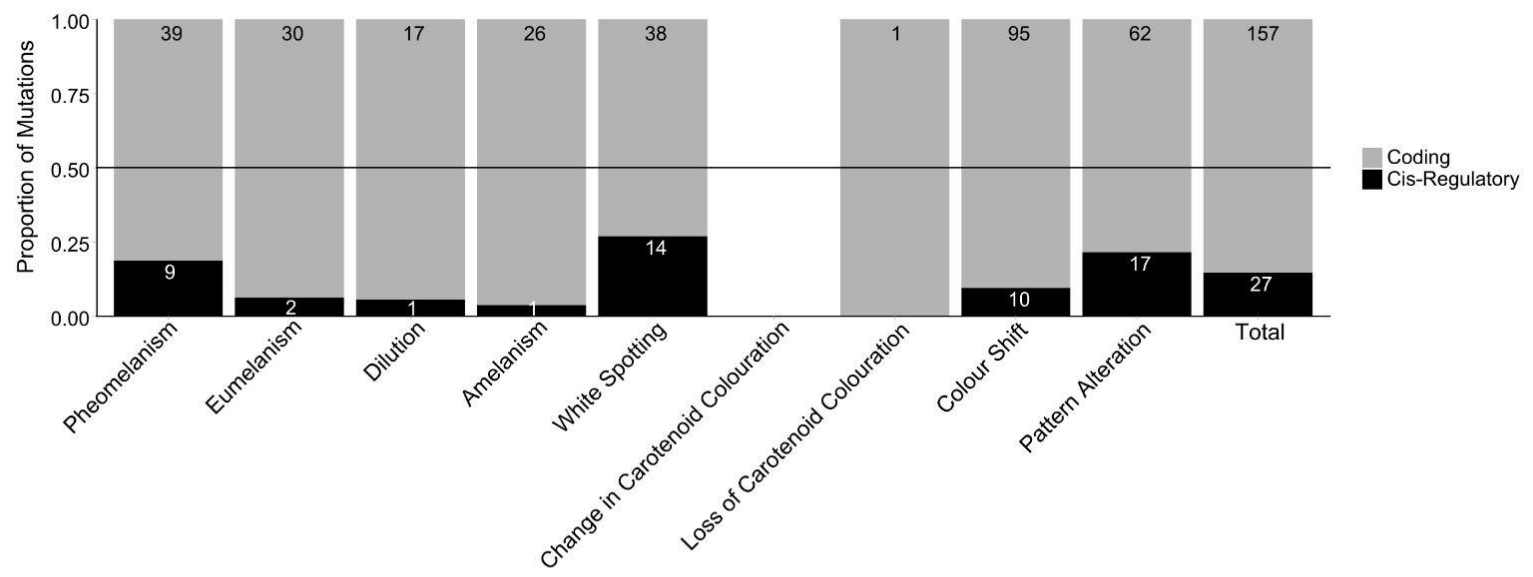

B Intraspecific

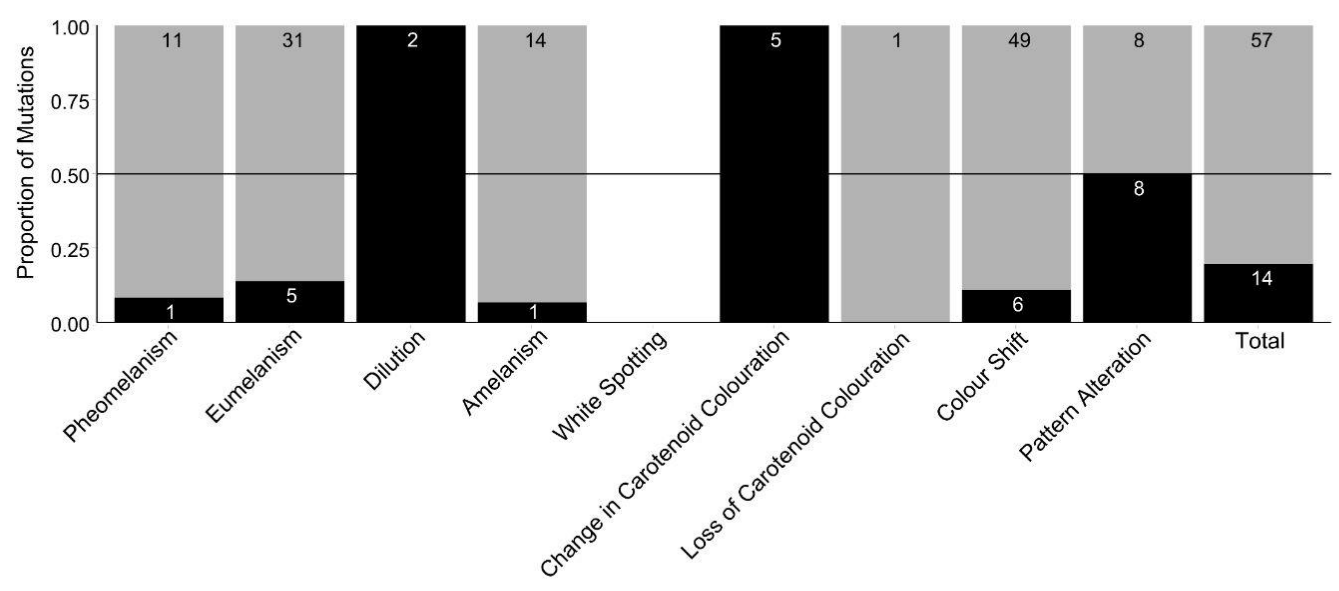

C Interspecific

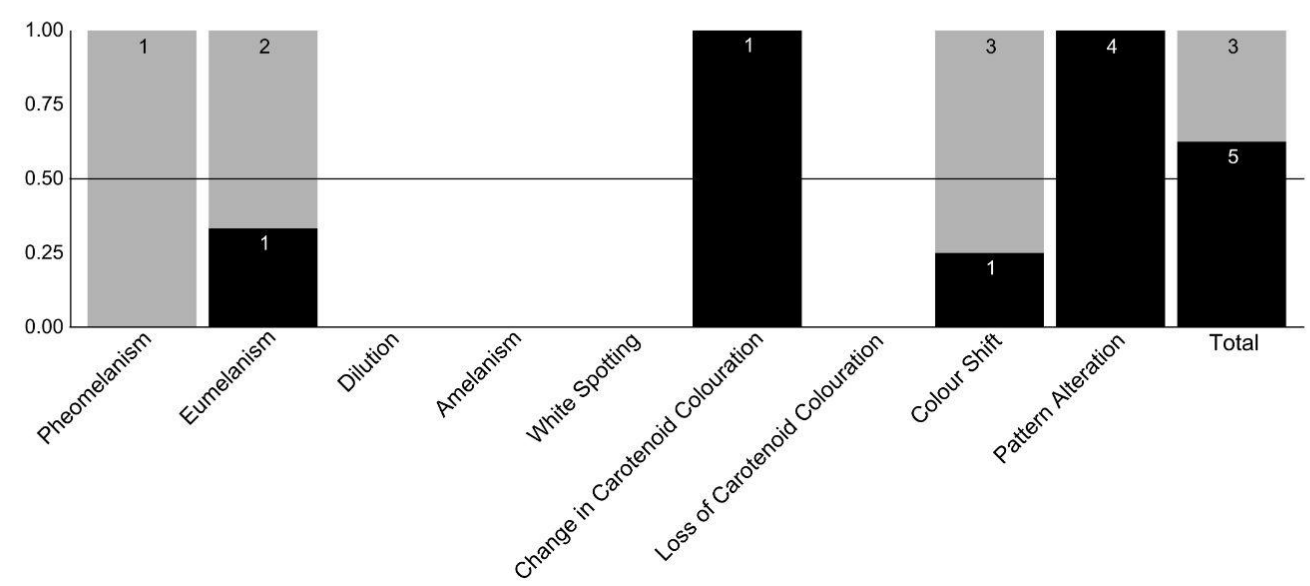

Figure $\mathbf{S} 3$ shows the proportion of cis-regulatory and coding mutations associated with 955 different phenotype categories and taxonomic statuses - A: Domesticated variation, B:

956 Intraspecific variation, and C: Interspecific variation. The total proportion for each taxonomic 
bioRxiv preprint doi: https://doi.org/10.1101/2022.01.01.474697; this version posted January $2,2022$. The copyright holder for this preprint

(which was not certified by peer review) is the author/funder, who has granted bioRxiv a license to display the preprint in perpetuity. It is made available under aCC-BY-NC-ND 4.0 International license.

957 status is shown. The numbers above each bar represent the number of entries in that

958 category. The grey horizontal line is at 0.5 . 


\section{Figure S4}

A Candidate Gene

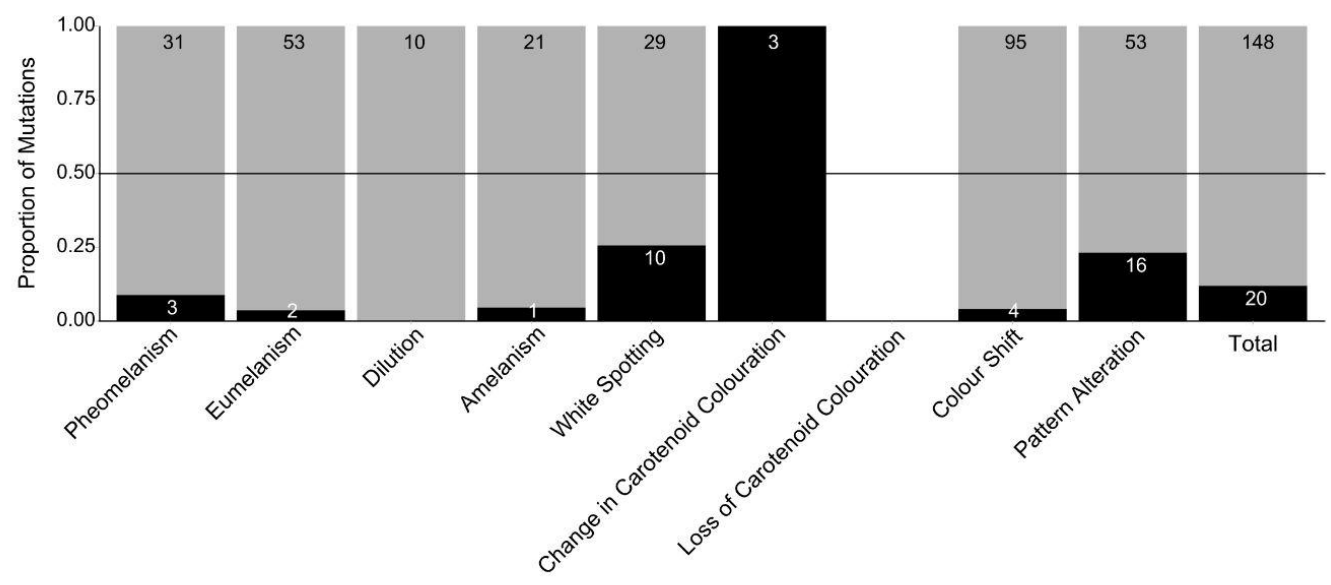

$\mathrm{B}$ Linkage mapping

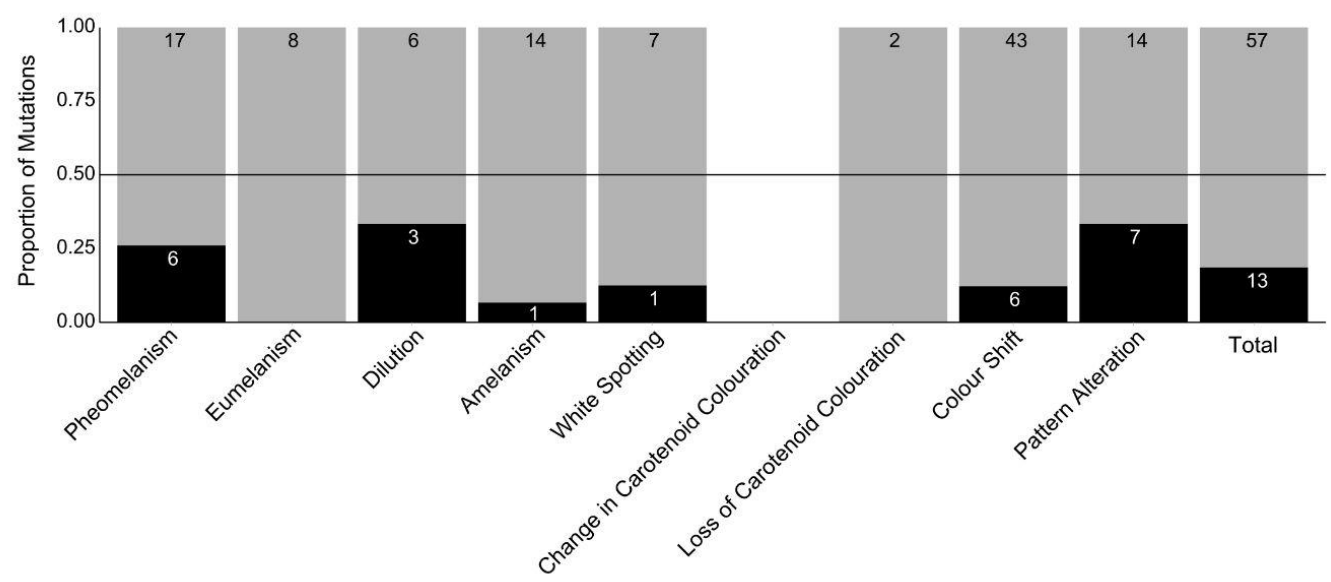

B Association mapping

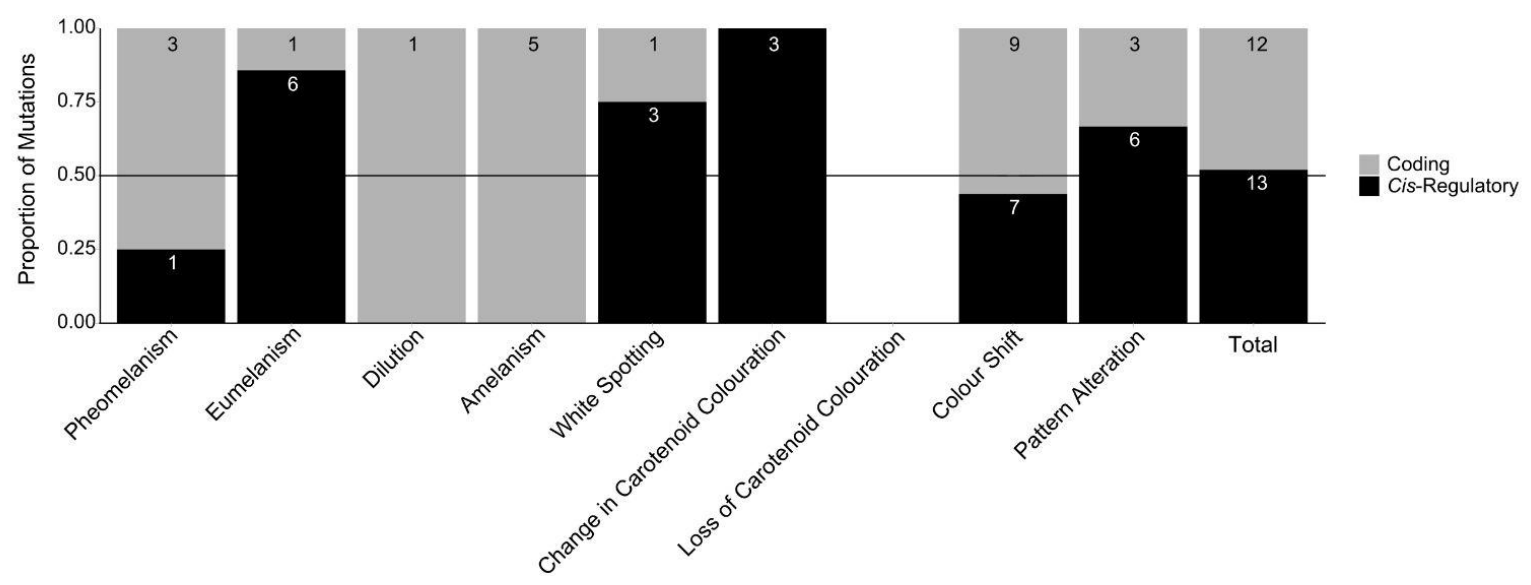

961 Figure S4 shows the proportion of cis-regulatory and coding mutations associated with
962 different phenotype categories and study methodologies A: Candidate Gene, B: Linkage

963 Mapping, and C: Association Mapping. The total proportion for each study methodology is 
bioRxiv preprint doi: https://doi.org/10.1101/2022.01.01.474697; this version posted January $2,2022$. The copyright holder for this preprint

(which was not certified by peer review) is the author/funder, who has granted bioRxiv a license to display the preprint in perpetuity. It is made available under aCC-BY-NC-ND 4.0 International license.

964 shown. The numbers above each bar represent the number of entries in that category. The

965 grey horizontal line is at 0.5 .

966

967 
968 Supplementary Table S1 shows the $10 \mathrm{GO}$ categories assigned to dataset entries, the total

969 number of genes to which each GO category was assigned and corresponding total number

970 of entries, the number of cis-regulatory entries to which each was assigned and

971 corresponding cis-regulatory proportion, and the child GO terms that were combined into the

972 category where relevant.

\begin{tabular}{|c|c|c|c|c|c|c|}
\hline Category Name & $\begin{array}{l}\text { Unique Genes } \\
\text { Assigned }\end{array}$ & $\begin{array}{l}\text { Total Entries } \\
\text { Assigned }\end{array}$ & $\begin{array}{l}\text { Cis-Regulatory } \\
\text { Entries }\end{array}$ & $\begin{array}{l}\text { Cis-Regulatory } \\
\text { Proportion }\end{array}$ & $\begin{array}{l}\text { Child GO } \\
\text { Categories }\end{array}$ & GO Term ID \\
\hline Catalytic Activity & 17 & 110 & 14 & 0.149 & $\begin{array}{l}\text { Transferase } \\
\text { Activity, } \\
\text { Oxidoreductase } \\
\text { Activity, } \\
\text { Hydrolase } \\
\text { Activity, } \\
\text { Ligase Activity }\end{array}$ & $\begin{array}{l}\text { GO:0016740, } \\
\text { GO:0016491, } \\
\text { GO:0016787, } \\
\text { GO:0016874 }\end{array}$ \\
\hline $\begin{array}{l}\text { Signaling } \\
\text { Receptor Binding }\end{array}$ & 14 & 56 & 21 & 0.447 & $\mathrm{~N} / \mathrm{A}$ & GO:0005102 \\
\hline $\begin{array}{l}\text { DNA Binding or } \\
\text { Transcription } \\
\text { Factor Activity }\end{array}$ & 11 & 23 & 16 & 0.789 & $\begin{array}{l}\text { DNA Binding, } \\
\text { Transcription } \\
\text { Factor Activity }\end{array}$ & $\begin{array}{l}\text { GO:0003677, } \\
\text { GO:0003700 }\end{array}$ \\
\hline $\begin{array}{l}\text { Signaling } \\
\text { Receptor Activity }\end{array}$ & 10 & 147 & 8 & 0.060 & $\mathrm{~N} / \mathrm{A}$ & GO:0038023 \\
\hline $\begin{array}{l}\text { Transporter } \\
\text { Activity }\end{array}$ & 10 & 39 & 5 & 0.135 & $\mathrm{~N} / \mathrm{A}$ & GO:0005215 \\
\hline Protein Binding & 7 & 33 & 9 & 0.300 & $\mathrm{~N} / \mathrm{A}$ & GO:0005515 \\
\hline $\begin{array}{l}\text { Carbohydrate } \\
\text { Derivative Binding }\end{array}$ & 6 & 54 & 7 & 0.163 & $N / A$ & GO:0097367 \\
\hline RNA Binding & 3 & 4 & 2 & 1 & $N / A$ & GO:0003723 \\
\hline $\begin{array}{l}\text { Enzyme Regulator } \\
\text { Activity }\end{array}$ & 3 & 3 & 1 & 0.500 & $N / A$ & GO:0030234 \\
\hline Lipid Binding & 2 & 2 & 0 & 0 & $N / A$ & GO:0008289 \\
\hline Totals & 83 & 471 & 83 & 0.216 & & \\
\hline
\end{tabular}




\section{$974 \quad$ Figure S5 - gene ontology assignments, unique genes and number of entries}

A

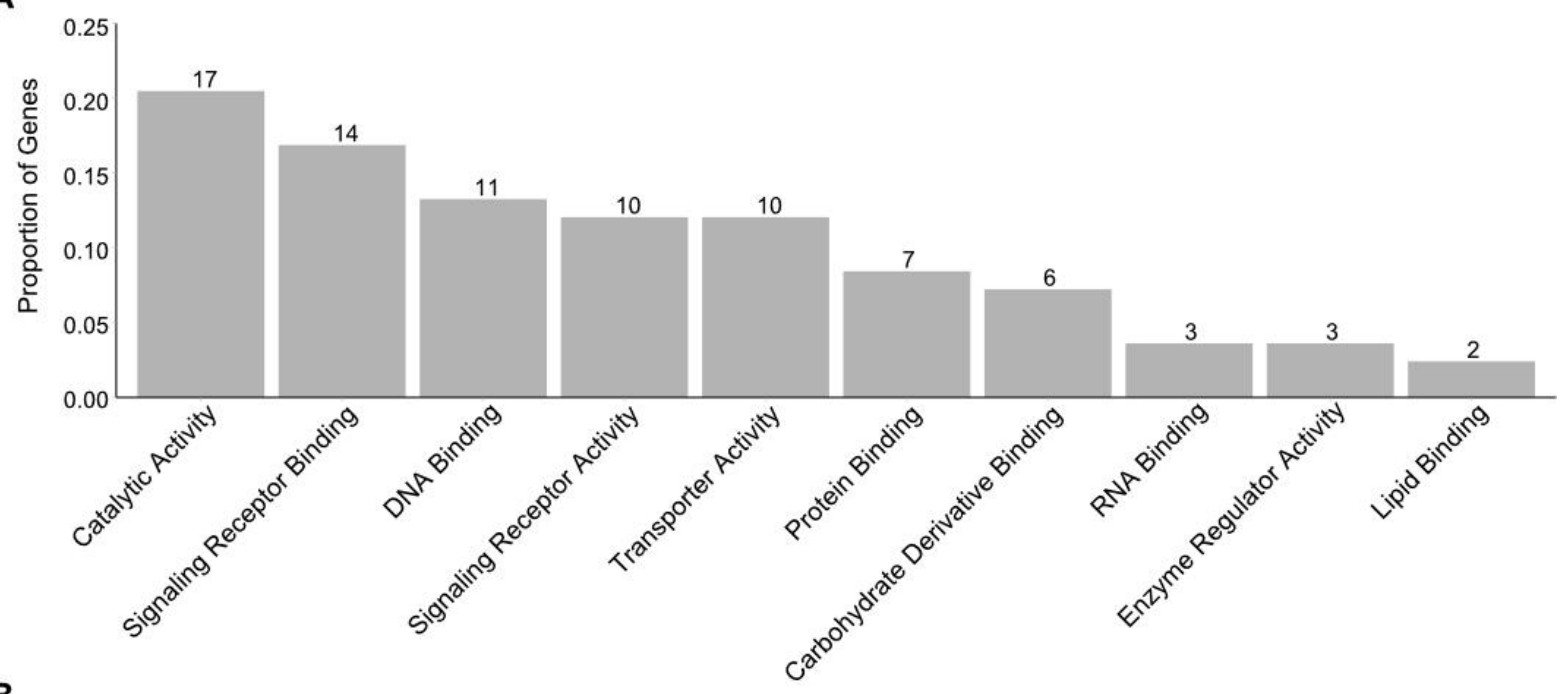

B

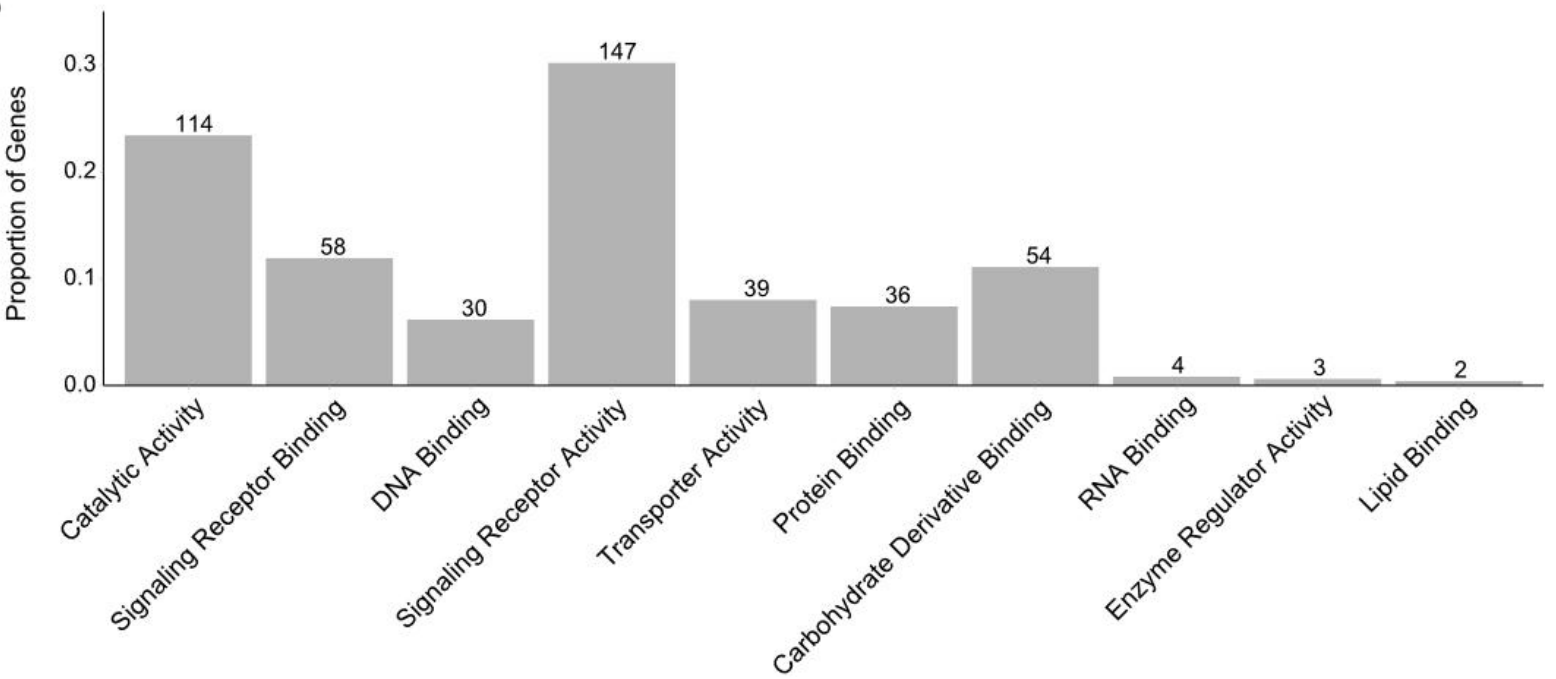

976 Figure S5, A: The proportion of unique genes that each GO category was assigned to. B:

977 The proportion of entries that each GO category was assigned to. The numbers above each

978 bar represent the number of genes or entries in that category. Note that the RNA Binding,

979 Enzyme Regulatory Activity, and Lipid Binding categories were removed for Figure 4C in the 980 main text due to their low numbers of assigned genes (see Methods). 
982 Supplementary Table S2 shows hotspot genes for each clade. For brevity, the 10 most

983 represented genes for each clade are displayed, excluding genes with equal numbers of

984 entries that would exceed this limit. For each gene, the number of entries in other clades is

985 shown. Full data is in the provided Supplementary File 1.

\begin{tabular}{|c|c|c|c|c|}
\hline Gene & $\begin{array}{l}\text { Number of } \\
\text { Mammal Entries }\end{array}$ & $\begin{array}{l}\text { Number of Bird } \\
\text { Entries }\end{array}$ & $\begin{array}{l}\text { Number of } \\
\text { Teleost Entries }\end{array}$ & $\begin{array}{l}\text { Number of } \\
\text { Squamate Entries }\end{array}$ \\
\hline \multicolumn{5}{|l|}{ Mammals } \\
\hline MC1R & 59 & 24 & 2 & 3 \\
\hline Kit & 49 & 0 & 0 & 0 \\
\hline Asip & 29 & 6 & 0 & 0 \\
\hline Tyr & 18 & 7 & 0 & 0 \\
\hline Tyrp1 & 14 & 2 & 0 & 0 \\
\hline SLC45A2 & 11 & 6 & 2 & 0 \\
\hline PMEL & 11 & 3 & 0 & 0 \\
\hline Mlph & 7 & 2 & 0 & 0 \\
\hline \multicolumn{5}{|l|}{ Birds } \\
\hline MC1R & 59 & 24 & 2 & 3 \\
\hline Tyr & 18 & 7 & 0 & 0 \\
\hline Asip & 11 & 6 & 2 & 0 \\
\hline SLC45A2 & 29 & 6 & 0 & 0 \\
\hline
\end{tabular}


bioRxiv preprint doi: https://doi.org/10.1101/2022.01.01.474697; this version posted January 2, 2022. The copyright holder for this preprint

(which was not certified by peer review) is the author/funder, who has granted bioRxiv a license to display the preprint in perpetuity. It is made available under aCC-BY-NC-ND 4.0 International license.

\begin{tabular}{|c|c|c|c|c|}
\hline PMEL & 11 & 3 & 0 & 0 \\
\hline Ndp & 0 & 3 & 0 & 0 \\
\hline Sox10 & 0 & 3 & 0 & 0 \\
\hline \multicolumn{5}{|l|}{ Teleosts } \\
\hline Pax7 & 0 & 0 & 4 & 0 \\
\hline Oca2 & 2 & 0 & 3 & 1 \\
\hline MC1R & 59 & 24 & 2 & 3 \\
\hline SLC45A2 & 11 & 6 & 2 & 0 \\
\hline \multicolumn{5}{|c|}{ Squamates } \\
\hline MC1R & 59 & 24 & 2 & 3 \\
\hline Oca2 & 2 & 0 & 3 & 1 \\
\hline BCO2 & 0 & 2 & 0 & 1 \\
\hline PREP & 0 & 0 & 0 & 1 \\
\hline Prkar1a & 0 & 0 & 0 & 1 \\
\hline Spr & 0 & 0 & 0 & 1 \\
\hline
\end{tabular}




\section{References}

988

989

990

991

992

993

994

995

996

997

998

999

1000

1001

1002

1003

1004

1005

1006

1007

1008

1009

1010

1011

1012

1013

1014

1015

1016

1017

1018

1019

1020

1021

1022

1023

1024

1025

1026

1027

1028

1029

1030

1031

1032

1033

1034

1035

1036

1037

1038

1039
Abitbol, M., Legrand, R., Tiret, L., 2014. A missense mutation in melanocortin 1 receptor is associated with the red coat colour in donkeys. Anim. Genet. 45, 878-880. https://doi.org/10.1111/age.12207

Adhikari, K., Mendoza-Revilla, J., Sohail, A., Fuentes-Guajardo, M., Lampert, J., ChacónDuque, J.C., Hurtado, M., Villegas, V., Granja, V., Acuña-Alonzo, V., Jaramillo, C., Arias, W., Lozano, R.B., Everardo, P., Gómez-Valdés, J., Villamil-Ramírez, H., Silva de Cerqueira, C.C., Hunemeier, T., Ramallo, V., Schuler-Faccini, L., Salzano, F.M., Gonzalez-José, R., Bortolini, M.-C., Canizales-Quinteros, S., Gallo, C., Poletti, G., Bedoya, G., Rothhammer, F., Tobin, D.J., Fumagalli, M., Balding, D., Ruiz-Linares, A., 2019. A GWAS in Latin Americans highlights the convergent evolution of lighter skin pigmentation in Eurasia. Nat. Commun. 10, 358. https://doi.org/10.1038/s41467018-08147-0

Andrade, P., Pinho, C., Lanuza, G.P. i de, Afonso, S., Brejcha, J., Rubin, C.-J., Wallerman, O., Pereira, P., Sabatino, S.J., Bellati, A., Pellitteri-Rosa, D., Bosakova, Z., Bunikis, I., Carretero, M.A., Feiner, N., Marsik, P., Paupério, F., Salvi, D., Soler, L., While, G.M., Uller, T., Font, E., Andersson, L., Carneiro, M., 2019. Regulatory changes in pterin and carotenoid genes underlie balanced color polymorphisms in the wall lizard. Proc. Natl. Acad. Sci. 116, 5633-5642. https://doi.org/10.1073/pnas.1820320116

Barrett, R.D.H., Hoekstra, H.E., 2011. Molecular spandrels: tests of adaptation at the genetic level. Nat. Rev. Genet. 12, 767-780. https://doi.org/10.1038/nrg3015

Bedford, N.L., Hoekstra, H.E., 2015. Peromyscus mice as a model for studying natural variation. eLife 4, e06813. https://doi.org/10.7554/eLife.06813

Buniello, A., MacArthur, J.A.L., Cerezo, M., Harris, L.W., Hayhurst, J., Malangone, C., McMahon, A., Morales, J., Mountjoy, E., Sollis, E., Suveges, D., Vrousgou, O., Whetzel, P.L., Amode, R., Guillen, J.A., Riat, H.S., Trevanion, S.J., Hall, P., Junkins, H., Flicek, P., Burdett, T., Hindorff, L.A., Cunningham, F., Parkinson, H., 2019. The NHGRI-EBI GWAS Catalog of published genome-wide association studies, targeted arrays and summary statistics 2019. Nucleic Acids Res. 47, D1005-D1012. https://doi.org/10.1093/nar/gky1120

Carroll, S.B., 2008. Evo-Devo and an Expanding Evolutionary Synthesis: A Genetic Theory of Morphological Evolution. Cell 134, 25-36. https://doi.org/10.1016/j.cell.2008.06.030

Chenoweth, S.F., McGuigan, K., 2010. The Genetic Basis of Sexually Selected Variation. Annu. Rev. Ecol. Evol. Syst. 41, 81-101. https://doi.org/10.1146/annurev-ecolsys102209-144657

Cieslak, M., Reissmann, M., Hofreiter, M., Ludwig, A., 2011. Colours of domestication. Biol. Rev. 86, 885-899. https://doi.org/10.1111/j.1469-185X.2011.00177.x

Conte, G.L., Arnegard, M.E., Peichel, C.L., Schluter, D., 2012. The probability of genetic parallelism and convergence in natural populations. Proc. R. Soc. B Biol. Sci. 279, 5039-5047. https://doi.org/10.1098/rspb.2012.2146

Cooke, T.F., Fischer, C.R., Wu, P., Jiang, T.-X., Xie, K.T., Kuo, J., Doctorov, E., Zehnder, A., Khosla, C., Chuong, C.-M., Bustamante, C.D., 2017. Genetic Mapping and Biochemical Basis of Yellow Feather Pigmentation in Budgerigars. Cell 171, 427439.e21. https://doi.org/10.1016/j.cell.2017.08.016

Courtier-Orgogozo, V., Arnoult, L., Prigent, S.R., Wiltgen, S., Martin, A., 2020. Gephebase, a database of genotype-phenotype relationships for natural and domesticated variation in Eukaryotes. Nucleic Acids Res. 48, D696-D703.

https://doi.org/10.1093/nar/gkz796

Courtier-Orgogozo, V., Martin, A., 2020. The coding loci of evolution and domestication: current knowledge and implications for bio-inspired genome editing. J. Exp. Biol. 223, jeb208934. https://doi.org/10.1242/jeb.208934

Crawford, N.G., Kelly, D.E., Hansen, M.E.B., Beltrame, M.H., Fan, S., Bowman, S.L., Jewett, 
E., Ranciaro, A., Thompson, S., Lo, Y., Pfeifer, S.P., Jensen, J.D., Campbell, M.C., Beggs, W., Hormozdiari, F., Mpoloka, S.W., Mokone, G.G., Nyambo, T., Meskel, D.W., Belay, G., Haut, J., NISC Comparative Sequencing Program, Rothschild, H., Zon, L., Zhou, Y., Kovacs, M.A., Xu, M., Zhang, T., Bishop, K., Sinclair, J., Rivas, C., Elliot, E., Choi, J., Li, S.A., Hicks, B., Burgess, S., Abnet, C., Watkins-Chow, D.E., Oceana, E., Song, Y.S., Eskin, E., Brown, K.M., Marks, M.S., Loftus, S.K., Pavan, W.J., Yeager, M., Chanock, S., Tishkoff, S.A., 2017. Loci associated with skin pigmentation identified in African populations. Science 358, eaan8433. https://doi.org/10.1126/science.aan8433

Cuthill, I.C., Allen, W.L., Arbuckle, K., Caspers, B., Chaplin, G., Hauber, M.E., Hill, G.E., Jablonski, N.G., Jiggins, C.D., Kelber, A., Mappes, J., Marshall, J., Merrill, R., Osorio, D., Prum, R., Roberts, N.W., Roulin, A., Rowland, H.M., Sherratt, T.N., Skelhorn, J., Speed, M.P., Stevens, M., Stoddard, M.C., Stuart-Fox, D., Talas, L., Tibbetts, E., Caro, T., 2017. The biology of color. Science 357, eaan0221. https://doi.org/10.1126/science.aan0221

Domyan, E.T., Guernsey, M.W., Kronenberg, Z., Krishnan, S., Boissy, R.E., Vickrey, A.I., Rodgers, C., Cassidy, P., Leachman, S.A., Fondon, J.W., Yandell, M., Shapiro, M.D., 2014. Epistatic and Combinatorial Effects of Pigmentary Gene Mutations in the Domestic Pigeon. Curr. Biol. 24, 459-464. https://doi.org/10.1016/j.cub.2014.01.020

Feng, Y., McQuillan, M.A., Tishkoff, S.A., 2021. Evolutionary genetics of skin pigmentation in African populations. Hum. Mol. Genet. 30, R88-R97. https://doi.org/10.1093/hmg/ddab007

García-Borrón, J.C., Sánchez-Laorden, B.L., Jiménez-Cervantes, C., 2005. Melanocortin-1 receptor structure and functional regulation. Pigment Cell Res. 18, 393-410. https://doi.org/10.1111/j.1600-0749.2005.00278.x

Gazda, M.A., Toomey, M.B., Araújo, P.M., Lopes, R.J., Afonso, S., Myers, C.A., Serres, K., Kiser, P.D., Hill, G.E., Corbo, J.C., Carneiro, M., 2020. Genetic Basis of De Novo Appearance of Carotenoid Ornamentation in Bare Parts of Canaries. Mol. Biol. Evol. 37, 1317-1328. https://doi.org/10.1093/molbev/msaa006

Gibert, J.-M., 2017. The flexible stem hypothesis: evidence from genetic data. Dev. Genes Evol. 227, 297-307. https://doi.org/10.1007/s00427-017-0589-0

Goda, M., Fujii, R., 1995. Blue Chromatophores in Two Species of Callionymid Fish. Zoolog. Sci. 12, 811-813. https://doi.org/10.2108/zsj.12.811

Gunnarsson, U., Kerje, S., Bed'hom, B., Sahlqvist, A.-S., Ekwall, O., Tixier-Boichard, M., Kämpe, O., Andersson, L., 2011. The Dark brown plumage color in chickens is caused by an 8.3-kb deletion upstream of SOX10. Pigment Cell Melanoma Res. 24, 268-274. https://doi.org/10.1111/j.1755-148X.2011.00825.x

Haase, B., Jagannathan, V., Rieder, S., Leeb, T., 2015. A novel KIT variant in an Icelandic horse with white-spotted coat colour. Anim. Genet. 46, 466-466. https://doi.org/10.1111/age.12313

Hanly, J.J., Livraghi, L., Heryanto, C., McMillan, W.O., Jiggins, C.D., Gilbert, L.E., Martin, A., 2021. A macromutation eliminates colour patterning in captive butterflies. bioRxiv https://doi.org/10.1101/2021.10.29.466422

Hédan, B., Cadieu, E., Botherel, N., Dufaure de Citres, C., Letko, A., Rimbault, M., Drögemüller, C., Jagannathan, V., Derrien, T., Schmutz, S., Leeb, T., André, C., 2019. Identification of a Missense Variant in MFSD12 Involved in Dilution of Phaeomelanin Leading to White or Cream Coat Color in Dogs. Genes 10, 386. https://doi.org/10.3390/genes10050386

Hedrick, P., 2015. Heterozygote advantage: the effect of artificial selection in livestock and pets. J. Hered, 106: 141-154. https://doi.org/10.1093/jhered/esu070

Hiragaki, T., Inoue-Murayama, M., Miwa, M., Fujiwara, A., Mizutani, M., Minvielle, F., Ito, S., 2008. Recessive black Is Allelic to the yellow Plumage Locus in Japanese Quail and Associated With a Frameshift Deletion in the ASIP Gene. Genetics 178, 771-775. https://doi.org/10.1534/genetics.107.077040

Hoekstra, H.E., 2006. Genetics, development and evolution of adaptive pigmentation in 
vertebrates. Heredity 97, 222-234. https://doi.org/10.1038/sj.hdy.6800861

Hoekstra, H.E., Coyne, J.A., 2007. The Locus of Evolution: Evo Devo and the Genetics of Adaptation. Evolution 61, 995-1016. https://doi.org/10.1111/j.15585646.2007.00105.x

Hou, L., Panthier, J.J., Arnheiter, H., 2000. Signaling and transcriptional regulation in the neural crest-derived melanocyte lineage: interactions between KIT and MITF. Dev. Camb. Engl. 127, 5379-5389. https://doi.org/10.1242/dev.127.24.5379

Hu, Z.-L., Park, C.A., Reecy, J.M., 2021. Bringing the Animal QTLdb and CorrDB into the future: meeting new challenges and providing updated services. Nucleic Acids Res. gkab1116. https://doi.org/10.1093/nar/gkab1116

Huang, D., Lewis, V.M., Foster, T.N., Toomey, M.B., Corbo, J.C., Parichy, D.M., 2021. Development and genetics of red coloration in the zebrafish relative Danio albolineatus. eLife 10, e70253. https://doi.org/10.7554/eLife.70253

Hubbard, J.K., Uy, J.A.C., Hauber, M.E., Hoekstra, H.E., Safran, R.J., 2010. Vertebrate pigmentation: from underlying genes to adaptive function. Trends Genet. 26, 231239. https://doi.org/10.1016/j.tig.2010.02.002

Johnston, S.E., Gratten, J., Berenos, C., Pilkington, J.G., Clutton-Brock, T.H., Pemberton, J.M., Slate, J., 2013. Life history trade-offs at a single locus maintain sexually selected genetic variation. Nature 502, 93-95. https://doi.org/10.1038/nature12489

Jones, M.R., Mills, L.S., Alves, P.C., Callahan, C.M., Alves, J.M., Lafferty, D.J.R., Jiggins, F.M., Jensen, J.D., Melo-Ferreira, J., Good, J.M., 2018. Adaptive introgression underlies polymorphic seasonal camouflage in snowshoe hares. Science 360, 13551358. https://doi.org/10.1126/science.aar5273

Kambe, Y., Tanikawa, T., Matsumoto, Y., Tomozawa, M., Aplin, K.P., Suzuki, H., 2011. Origin of agouti-melanistic polymorphism in Wild Black Rats (Rattus rattus) inferred from Mc1r gene sequences. Zoolog. Sci. 28, 560-567. https://doi.org/10.2108/zsj.28.560

Kelsh, R.N., Harris, M.L., Colanesi, S., Erickson, C.A., 2009. Stripes and belly-spots - a review of pigment cell morphogenesis in vertebrates. Semin. Cell Dev. Biol. 20, 90 104. https://doi.org/10.1016/j.semcdb.2008.10.001

Kratochwil, C.F., Liang, Y., Gerwin, J., Woltering, J.M., Urban, S., Henning, F., MachadoSchiaffino, G., Hulsey, C.D., Meyer, A., 2018. Agouti-related peptide 2 facilitates convergent evolution of stripe patterns across cichlid fish radiations. Science 362 , 457-460. https://doi.org/10.1126/science.aao6809

Kratochwil, C.F., Meyer, A., 2015. Closing the genotype-phenotype gap: Emerging technologies for evolutionary genetics in ecological model vertebrate systems. BioEssays 37, 213-226. https://doi.org/10.1002/bies.201400142

Kronforst, M.R., Barsh, G.S., Kopp, A., Mallet, J., Monteiro, A., Mullen, S.P., Protas, M., Rosenblum, E.B., Schneider, C.J., Hoekstra, H.E., 2012. Unraveling the thread of nature's tapestry: the genetics of diversity and convergence in animal pigmentation. Pigment Cell Melanoma Res. 25, 411-433. https://doi.org/10.1111/j.1755148X.2012.01014.X

Lapedriza, A., Petratou, K., Kelsh, R.N., 2014. Chapter 14 - Neural Crest Cells and Pigmentation, in: Trainor, P.A. (Ed.), Neural Crest Cells. Academic Press, Boston, pp. 287-311. https://doi.org/10.1016/B978-0-12-401730-6.00015-6

Lehner, S., Gähle, M., Dierks, C., Stelter, R., Gerber, J., Brehm, R., Distl, O., 2013. TwoExon Skipping within MLPH Is Associated with Coat Color Dilution in Rabbits. PLOS ONE 8, e84525. https://doi.org/10.1371/journal.pone.0084525

Lenffer, J., Nicholas, F.W., Castle, K., Rao, A., Gregory, S., Poidinger, M., Mailman, M.D., Ranganathan, S., 2006. OMIA (Online Mendelian Inheritance in Animals): an enhanced platform and integration into the Entrez search interface at NCBI. Nucleic Acids Res. 34, D599-D601. https://doi.org/10.1093/nar/gkj152

Lewis, V.M., Saunders, L.M., Larson, T.A., Bain, E.J., Sturiale, S.L., Gur, D., Chowdhury, S., Flynn, J.D., Allen, M.C., Deheyn, D.D., Lee, J.C., Simon, J.A., Lippincott-Schwartz, J., Raible, D.W., Parichy, D.M., 2019. Fate plasticity and reprogramming in 
genetically distinct populations of Danio leucophores. Proc. Natl. Acad. Sci. 116, 11806-11811. https://doi.org/10.1073/pnas.1901021116

Lona-Durazo, F., Hernandez-Pacheco, N., Fan, S., Zhang, T., Choi, J., Kovacs, M.A., Loftus, S.K., Le, P., Edwards, M., Fortes-Lima, C.A., Eng, C., Huntsman, S., Hu, D., GómezCabezas, E.J., Marín-Padrón, L.C., Grauholm, J., Mors, O., Burchard, E.G., Norton, H.L., Pavan, W.J., Brown, K.M., Tishkoff, S., Pino-Yanes, M., Beleza, S., MarchecoTeruel, B., Parra, E.J., 2019. Meta-analysis of GWA studies provides new insights on the genetic architecture of skin pigmentation in recently admixed populations. BMC Genet. 20, 59. https://doi.org/10.1186/s12863-019-0765-5

Lopes, R.J., Johnson, J.D., Toomey, M.B., Ferreira, M.S., Araujo, P.M., Melo-Ferreira, J., Andersson, L., Hill, G.E., Corbo, J.C., Carneiro, M., 2016. Genetic Basis for Red Coloration in Birds. Curr. Biol. 26, 1427-1434.

https://doi.org/10.1016/j.cub.2016.03.076

Martin, A., Courtier-Orgogozo, V., 2017. Morphological Evolution Repeatedly Caused by Mutations in Signaling Ligand Genes, in: Sekimura, T., Nijhout, H.F. (Eds.), Diversity and Evolution of Butterfly Wing Patterns: An Integrative Approach. Springer, Singapore, pp. 59-87. https://doi.org/10.1007/978-981-10-4956-9_4

Martin, A., Orgogozo, V., 2013. The Loci of Repeated Evolution: A Catalog of Genetic Hotspots of Phenotypic Variation. Evolution 67, 1235-1250. https://doi.org/10.1111/evo.12081

McNamara, M.E., Rossi, V., Slater, T.S., Rogers, C.S., Ducrest, A.-L., Dubey, S., Roulin, A., 2021. Decoding the Evolution of Melanin in Vertebrates. Trends Ecol. Evol. 36, 430443. https://doi.org/10.1016/j.tree.2020.12.012

Metallinos, D.L., Bowling, A.T., Rine, J., 1998. A missense mutation in the endothelin-B receptor gene is associated with Lethal White Foal Syndrome: an equine version of Hirschsprung Disease. Mamm. Genome 9, 426-431. https://doi.org/10.1007/s003359900790

Miller, C.T., Beleza, S., Pollen, A.A., Schluter, D., Kittles, R.A., Shriver, M.D., Kingsley, D.M., 2007. cis-Regulatory Changes in Kit Ligand Expression and Parallel Evolution of Pigmentation in Sticklebacks and Humans. Cell 131, 1179-1189. https://doi.org/10.1016/j.cell.2007.10.055

Miura, I., Tagami, M., Fujitani, T., Ogata, M., 2017. Spontaneous tyrosinase mutations identified in albinos of three wild frog species. Genes Genet. Syst. 92, 189-196. https://doi.org/10.1266/ggs.16-00061

Orteu, A., Jiggins, C.D., 2020. The genomics of coloration provides insights into adaptive evolution. Nat. Rev. Genet. 21, 461-475. https://doi.org/10.1038/s41576-020-0234-z

Pál, C., Papp, B., Lercher, M.J., 2006. An integrated view of protein evolution. Nat. Rev. Genet. 7, 337-348. https://doi.org/10.1038/nrg1838

Parichy, D.M., 2021. Evolution of pigment cells and patterns: recent insights from teleost fishes. Curr. Opin. Genet. Dev. 69, 88-96. https://doi.org/10.1016/j.gde.2021.02.006

Patterson, L.B., Bain, E.J., Parichy, D.M., 2014. Pigment cell interactions and differential xanthophore recruitment underlying zebrafish stripe reiteration and Danio pattern evolution. Nat. Commun. 5, 5299. https://doi.org/10.1038/ncomms6299

Pfeifer, S.P., Laurent, S., Sousa, V.C., Linnen, C.R., Foll, M., Excoffier, L., Hoekstra, H.E., Jensen, J.D., 2018. The Evolutionary History of Nebraska Deer Mice: Local Adaptation in the Face of Strong Gene Flow. Mol. Biol. Evol. 35, 792-806. https://doi.org/10.1093/molbev/msy004

Protas, M.E., Patel, N.H., 2008. Evolution of Coloration Patterns. Annu. Rev. Cell Dev. Biol. 24, 425-446. https://doi.org/10.1146/annurev.cellbio.24.110707.175302

Robbins, L.S., Nadeau, J.H., Johnson, K.R., Kelly, M.A., Roselli-Rehfuss, L., Baack, E., Mountjoy, K.G., Cone, R.D., 1993. Pigmentation phenotypes of variant extension locus alleles result from point mutations that alter $\mathrm{MSH}$ receptor function. Cell 72 , 827-834. https://doi.org/10.1016/0092-8674(93)90572-8

Roberts, R.B., Ser, J.R., Kocher, T.D., 2009. Sexual Conflict Resolved by Invasion of a Novel Sex Determiner in Lake Malawi Cichlid Fishes. Science 326, 998-1001. 
https://doi.org/10.1126/science.1174705

Rockman, M.V., 2012. The Qtn Program and the Alleles That Matter for Evolution: All That's Gold Does Not Glitter. Evolution 66, 1-17. https://doi.org/10.1111/j.15585646.2011.01486.x

Rudh, A., Qvarnström, A., 2013. Adaptive colouration in amphibians. Semin. Cell Dev. Biol., Genetic basis and evolutionary causes of colour variation in vertebrates $24,553-561$. https://doi.org/10.1016/j.semcdb.2013.05.004

Sarkar, A., Hochedlinger, K., 2013. The Sox Family of Transcription Factors: Versatile Regulators of Stem and Progenitor Cell Fate. Cell Stem Cell 12, 15-30. https://doi.org/10.1016/j.stem.2012.12.007

Schneider, A., David, V.A., Johnson, W.E., O'Brien, S.J., Barsh, G.S., Menotti-Raymond, M., Eizirik, E., 2012. How the Leopard Hides Its Spots: ASIP Mutations and Melanism in Wild Cats. PLOS ONE 7, e50386. https://doi.org/10.1371/journal.pone.0050386

Shefchek, K.A., Harris, N.L., Gargano, M., Matentzoglu, N., Unni, D., Brush, M., Keith, D., Conlin, T., Vasilevsky, N., Zhang, X.A., Balhoff, J.P., Babb, L., Bello, S.M., Blau, H., Bradford, Y., Carbon, S., Carmody, L., Chan, L.E., Cipriani, V., Cuzick, A., Della Rocca, M., Dunn, N., Essaid, S., Fey, P., Grove, C., Gourdine, J.-P., Hamosh, A., Harris, M., Helbig, I., Hoatlin, M., Joachimiak, M., Jupp, S., Lett, K.B., Lewis, S.E., McNamara, C., Pendlington, Z.M., Pilgrim, C., Putman, T., Ravanmehr, V., Reese, J., Riggs, E., Robb, S., Roncaglia, P., Seager, J., Segerdell, E., Similuk, M., Storm, A.L., Thaxon, C., Thessen, A., Jacobsen, J.O.B., McMurry, J.A., Groza, T., Köhler, S., Smedley, D., Robinson, P.N., Mungall, C.J., Haendel, M.A., Munoz-Torres, M.C., Osumi-Sutherland, D., 2020. The Monarch Initiative in 2019: an integrative data and analytic platform connecting phenotypes to genotypes across species. Nucleic Acids Res. 48, D704-D715. https://doi.org/10.1093/nar/gkz997

Simões-Costa, M., Bronner, M.E., 2015. Establishing neural crest identity: a gene regulatory recipe. Development 142, 242-257. https://doi.org/10.1242/dev.105445

Singh, A.P., Nüsslein-Volhard, C., 2015. Zebrafish Stripes as a Model for Vertebrate Colour Pattern Formation. Curr. Biol. 25, R81-R92. https://doi.org/10.1016/j.cub.2014.11.013

Slate, J., 2013. From Beavis to Beak Color: A Simulation Study to Examine How Much Qtl Mapping Can Reveal About the Genetic Architecture of Quantitative Traits. Evolution 67, 1251-1262. https://doi.org/10.1111/evo.12060

Spiewak, J.E., Bain, E.J., Liu, J., Kou, K., Sturiale, S.L., Patterson, L.B., Diba, P., Eisen, J.S., Braasch, I., Ganz, J., Parichy, D.M., 2018. Evolution of Endothelin signaling and diversification of adult pigment pattern in Danio fishes. PLOS Genet. 14, e1007538. https://doi.org/10.1371/journal.pgen.1007538

Stern, D.L., Orgogozo, V., 2009. Is Genetic Evolution Predictable? Science 323, 746-751. https://doi.org/10.1126/science.1158997

Stern, D.L., Orgogozo, V., 2008. The Loci of Evolution: How Predictable Is Genetic Evolution? Evolution 62, 2155-2177. https://doi.org/10.1111/j.15585646.2008.00450.x

Tanaka, J., Leeb, T., Rushton, J., Famula, T.R., Mack, M., Jagannathan, V., Flury, C., Bachmann, I., Eberth, J., McDonnell, S.M., Penedo, M.C.T., Bellone, R.R., 2019. Frameshift Variant in MFSD12 Explains the Mushroom Coat Color Dilution in Shetland Ponies. Genes 10, 826. https://doi.org/10.3390/genes10100826

Toews, D.P.L., Hofmeister, N.R., Taylor, S.A., 2017. The Evolution and Genetics of Carotenoid Processing in Animals. Trends Genet. 33, 171-182. https://doi.org/10.1016/j.tig.2017.01.002

Toews, D.P.L., Taylor, S.A., Vallender, R., Brelsford, A., Butcher, B.G., Messer, P.W., Lovette, I.J., 2016. Plumage Genes and Little Else Distinguish the Genomes of Hybridizing Warblers. Curr. Biol. 26, 2313-2318.

https://doi.org/10.1016/j.cub.2016.06.034

Toomey, M.B., Lopes, R.J., Araújo, P.M., Johnson, J.D., Gazda, M.A., Afonso, S., Mota, P.G., Koch, R.E., Hill, G.E., Corbo, J.C., Carneiro, M., 2017. High-density lipoprotein 
receptor SCARB1 is required for carotenoid coloration in birds. Proc. Natl. Acad. Sci. 114, 5219-5224. https://doi.org/10.1073/pnas.1700751114 S., Lopes, R.J., Corbo, J.C., Carneiro, M., 2018. A non-coding region near Follistatin controls head colour polymorphism in the Gouldian finch. Proc. R. Soc. B Biol. Sci. 285, 20181788. https://doi.org/10.1098/rspb.2018.1788

Worth, C.L., Gong, S., Blundell, T.L., 2009. Structural and functional constraints in the evolution of protein families. Nat. Rev. Mol. Cell Biol. 10, 709-720. https://doi.org/10.1038/nrm2762 